\title{
Evolution, pattern, and partitioning of deformation during oblique continental rifting: Inferences from lithospheric-scale centrifuge models
}

\author{
Andrea Agostini \\ Dipartimento di Scienze della Terra, Università degli Studi di Firenze, Via G. La Pira, 4, I-50121 Florence, Italy
}

\section{Giacomo Corti}

Istituto di Geoscienze e Georisorse, Unità Operativa Firenze, Consiglio Nazionale delle Ricerche, Via G. La Pira, 4, I-50121 Florence, Italy (giacomo.corti@unifi.it)

\author{
Antonio Zeoli \\ Museo Nazionale Antartide, Via Laterino 8, I-53100 Siena, Italy
}

\section{Genene Mulugeta}

Baltic University Programme, Department of Earth Sciences, Uppsala University, Villavagen 16, SE-75236 Uppsala, Sweden

[1] Oblique rifting is investigated through centrifuge experiments that reproduce extension of a continental lithosphere containing a preexisting weakness zone. During extension, this weakness localizes deformation, and different rift obliquity is obtained by varying its trend with respect to the stretching direction. Model results show that deformation is mostly controlled by the obliquity angle $\alpha$ (defined as the angle between the orthogonal to the rift trend and the extension direction). For low obliquity $\left(\alpha<45^{\circ}\right)$, rifting is initially characterized by activation of large, en echelon boundary faults bordering a subsiding rift depression, with no deformation affecting the rift floor. Increasing extension results in the abandonment of the boundary faults and the development of new faults within the rift depression. These faults are orthogonal to the direction of extension and arranged in two en echelon segments linked by a complex transfer zones, characterized by strike-slip component of motion. In these models, a strong strain partitioning is observed between the rift margins, where the boundary fault systems have an oblique-slip motion, and the valley floor that away from the transfer zones is affected by a pure extension. Moderate obliquity $\left(\alpha=45^{\circ}\right)$ still results in a two-phase rift evolution, although boundary fault activity is strongly reduced, and deformation is soon transferred to the rift depression. The fault pattern is similar to that of low-obliquity models, although internal faults become slightly oblique to the orthogonal to the direction of extension. Deformation partitioning between the rift margins and the valley floor is still observed but is less developed than for low-obliquity rifting. For high obliquity $\left(\alpha>45^{\circ}\right)$, no boundary faults form, and the extensional deformation affects the rift depression since early stages of extension. Dominance of the strike-slip motion over extension leads to the development of oblique-slip and nearly pure strike-slip faults, oblique to both the rift trend and the orthogonal to the extension direction, with no strain partitioning between the margins and the rift floor. These results suggest that oblique reactivation of preexisting weaknesses plays a major role in controlling rift evolution, architecture, and strain partitioning, findings that have a significant relevance for natural oblique rifts. 
Components: 11,907 words, 9 figures.

Keywords: oblique rifting; extensional deformation; rift architecture; strain partitioning.

Index Terms: 8109 Tectonophysics: Continental tectonics: extensional (0905); 8120 Tectonophysics: Dynamics of lithosphere and mantle: general (1213); 8118 Tectonophysics: Dynamics and mechanics of faulting (8004).

Received 29 June 2009; Revised 15 September 2009; Accepted 22 September 2009; Published 26 November 2009.

Agostini, A., G. Corti, A. Zeoli, and G. Mulugeta (2009), Evolution, pattern, and partitioning of deformation during oblique continental rifting: Inferences from lithospheric-scale centrifuge models, Geochem. Geophys. Geosyst., 10, Q11015, doi:10.1029/2009GC002676.

\section{Introduction}

[2] Oblique rifting occurs when the direction of displacement between two rigid plates is oblique to the deformation zone. This normally arises because of the reactivation of preexisting crustal or lithospheric zone of weakness trending oblique to the stretching vector; however, oblique rifting may also result from a rotation of the direction of extension through time in the so-called polyphase rifts [e.g., Bonini et al., 1997].

[3] Oblique rifting occurs both in continental and oceanic domains [e.g., Mart and Dauteuil, 2000, and references therein] and, since the deformed zone trends obliquely to the stretching vector, both extension perpendicular to the rift trend and shear parallel to the rift axis contribute to rift formation [e.g., Withjack and Jamison, 1986]. Analytical studies have shown that in oblique deformation settings the principal strain directions are generally not parallel to the direction of relative motion between the extending plates [e.g., Fournier and Petit, 2007, and references therein]. As a consequence of the complex kinematical boundary conditions, oblique rifts are characterized by composite fault patterns made of en echelon fault systems with dip-slip and/or oblique- to strike-slip kinematics and variable orientation with respect to the stretching vector. Scaled analog models [Withjack and Jamison, 1986; Tron and Brun, 1991; Smith and Durney, 1992; Dauteuil and Brun, 1993; McClay and White, 1995; Mart and Dauteuil, 2000; Clifton et al., 2000; Clifton and Schlische, 2001; Corti et al., 2001; McClay et al., 2002] have been successfully applied to the analysis of these fault patterns. These modeling works, mostly focused on the analysis of the deformation of a brittle upper crust, suggest that the main parameter controlling the final surface structural pattern is the angle between the extension vector and the rift trend (i.e., angle of obliquity, $\alpha$ ). Rift obliquity controls indeed the ratio between shearing and orthogonal stretching components of motion and, consequently, the orientation and relative proportion of normal and strike-slip faults.

[4] In this paper, the previous modeling results are expanded by using new lithospheric-scale analog experiments run in a centrifuge. Building on a previous experimental work [Corti, 2008], these new models adopt a complex brittle-ductile rheological multilayering as analog of the continental lithosphere and represent a step forward in modeling oblique rifting as they allow us to shed new light on the evolution, pattern and partitioning of deformation resulting from these complex kinematic boundary conditions.

\section{Experimental Modeling}

\subsection{Model Setup}

[5] The experiments were performed in an artificial gravity field of $\sim 18 \mathrm{~g}$ by using the large capacity centrifuge at the Tectonic Modeling Laboratory of the Institute of Geosciences and Earth Resources (National Research Council of Italy) at the Earth Sciences Department of the University of Florence. Following the setup adopted by Corti [2008], the models reproduced the upper part of the continental lithosphere (crust + upper lithospheric mantle) floating above a low-viscosity material simulating the asthenosphere (Figure 1a). They were built inside a transparent rectangular Plexiglas box and confined by two moveable sidewalls; removal of rectangular blocks (spacers) at the sides of these moving walls allowed vertical thinning and lateral expansion of the models in response to the centrifugal forces to fill the empty space (Figure 1a). Sequential removal of spacers during successive runs in the centrifuge allowed us to control the 

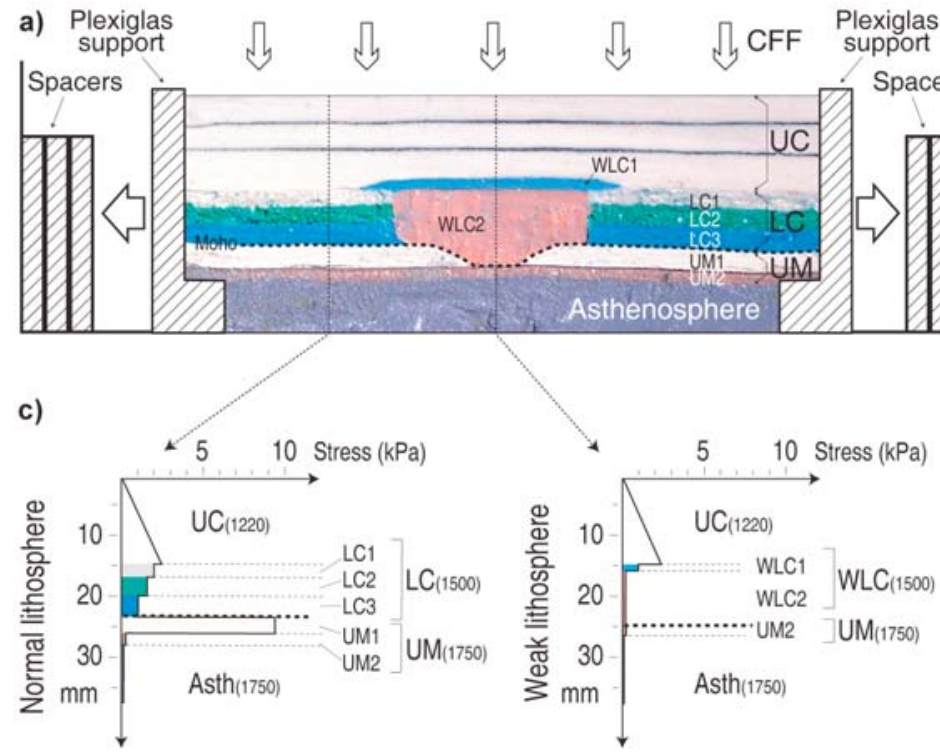

d)

b)
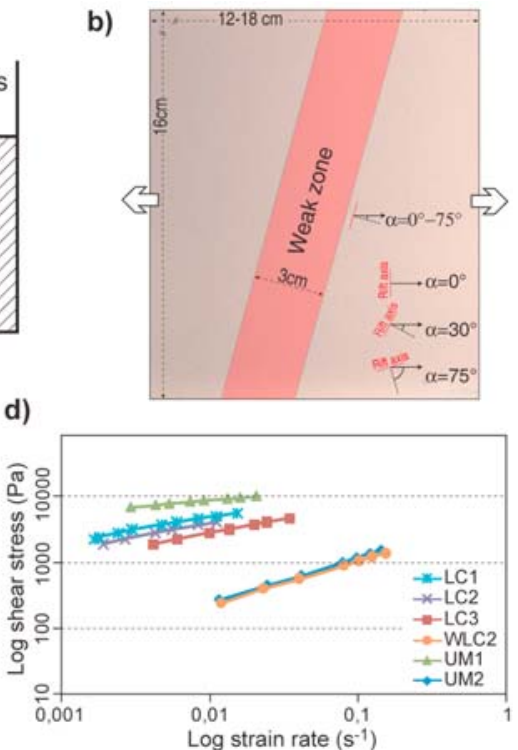

Figure 1. Setup of the lithospheric scale of oblique rifting. (a) Model cross section illustrating the vertical rheological layering and schematic representation of the extension conditions in the experimental apparatus. The models were built inside a transparent rectangular Plexiglas box (with internal dimensions of $25 \times 16 \times 7 \mathrm{~cm}$ ) and confined by two moveable Plexiglas supports; removal of rectangular blocks (spacers) at the sides of these moving walls allowed vertical thinning and lateral expansion of the models in response to the centrifugal forces (CFF) to fill the empty space (Figure 1a). Sequential removal of spacers during successive runs in the centrifuge allowed us to control the amount and rate of extension. Top view photos and laser scans of the models were taken after the end of each centrifuge run. After a successful experiment, the models were frozen before taking a number of cross sections to study their 3-D internal geometry. LC1-LC3, lower crustal layers 1-3; UM1 and UM2, upper mantle layers 1 and 2; WLC1 and WLC2, weak lower crustal layers 1 and 2. (b) Top view photo of the models, showing the obliquity of the weak zone with respect to the orthogonal to the stretching vector and the resulting angle $\alpha$. (c) Strength profiles of the model lithosphere (see Text S1 in the auxiliary material for calculations of strength profiles). UC, upper crust; Asth, asthenosphere; other abbreviations are as in Figure 1a. Numbers in brackets indicate the density of the different materials in $\mathrm{kg} \mathrm{m}^{-3}$. (d) Stress/strain rate relationships for the different ductile materials used to simulate the continental lithosphere plotted in a $\log / \log$ graph. Abbreviations are as in Figure 1a. Note the increase in the resistance of the ductile materials passing from UM2 and WLC2 to UM1.

amount and rate of extension [see Corti et al., 2003].

[6] In order to model oblique rifting conditions, the experimental lithosphere contained a central weakness zone that localizes deformation during progressive extension [see van Wijk, 2005; Corti, 2008]; the trend of this weakness (with respect to the extension direction) was varied in different experiment, to reproduce different obliquity angles $\alpha$ (i.e., angle between the orthogonal to the rift trend and the direction of extension) from $0^{\circ}$ to $75^{\circ}$, at increments of $15^{\circ}$ (Figure $1 \mathrm{~b}$ ). With this setup, the centrifuge forces impose a uniform stress field on the models and the distribution of deformation is imposed by the lateral variation in rheology and strength due to the presence of the weakness zone [e.g., Mulugeta and Ghebreab, 2001; Corti, 2008]. This represents a reasonable approximation of the natural process of continental rifting at a regional scale, where extensional stresses are applied to a predeformed, anisotropic lithosphere and deformation is not randomly distributed but tends to follow the trend of preexisting weaknesses inherited from previous deformation phases avoiding stronger regions [e.g., Dunbar and Sawyer, 1989; Versfelt and Rosendahl, 1989; Morley, 1999a; Tommasi and Vauchez, 2001; Ziegler and Cloetingh, 2004; van Wijk, 2005] (see also section 4.2 for the discussion on the role of inherited lithospheric-scale weaknesses evidenced by recent geophysical findings in the East African Rift).

[7] On average, five different models were performed for each angle of obliquity. Although the models may have differed in small details, the first-order deformation pattern and evolution were always comparable. 


\subsection{Rheological Layering and Experimental Materials}

[8] Building on previous numerical modeling [ $\mathrm{van}$ Wijk, 2005], the models reproduced the complex brittle-ductile rheological multilayering characteristics of the extending continental lithosphere (Figure 1c). The brittle upper crust UC was simulated by a K-feldspar powder, showing a linear increasing in the strength with depth (see Table S1 in the auxiliary material for material characteristics). ${ }^{1}$ The ductile lower portion of the crust was made by three different levels (LC1, LC2, LC3), with the same density but decreasing viscosity (strength) with depth (Figure 1d). This setup allows us to approximate the temperaturerelated decrease in strength with depth in natural ductile layers, thus improving previous models of continental extension where a depth-independent behavior of ductile layers was modeled (see reviews by Brun [1999] or Corti et al. [2003]). These layers were made of a mixture of plasticine (Pongo modeling dough, distributed by FILA) and Polydimethylsiloxane (silicone SGM36 distributed by Dow Corning, hereafter referred to as PDMS) (100:45\% in weight). Plasticines with different colors were used to model the ductile layers with decrease in strength with depth: the different color corresponds indeed to a different viscosity that decreases passing from white to blue to green plasticine (Figure 1d).

[9] The upper lithospheric mantle was made by two different layers with decreasing strength (and constant density) with depth (Figure 1d). The strong uppermost mantle layer (UM1) was made of a mixture of white plasticine and PDMS (100:20\% in weight), whereas the underlying layer (UM2) was made of a mixture of silicone (Wacker Silicone Bouncing Putty 29 distributed by CRC France, hereafter referred to as Wacker BP29), corundum sand and oleic acid (100:100:5\% in weight, respectively). As in previous modeling [e.g., van Wijk, 2005; Corti, 2008], this layering assumes that resistance in the mantle decreases rapidly with depth, and most of the strength is retained in a strong uppermost layer.

[10] Following previous analog [e.g., Corti and Manetti, 2006; Corti, 2008] and numerical [van Wijk, 2005] models, the weak zone in the center of the models was modeled by considering a local increase in crustal thickness (analogous to the

${ }^{1}$ Auxiliary materials are available in the HTML. doi:10.1029/ 2009GC002676. presence of a preexisting crustal root), which is expected to greatly reduce the integrated resistance of the lithosphere by (1) replacing the strong lithospheric mantle material with weak crustal material and (2) increasing initial Moho temperatures and thus softening the crustal materials with respect to the surroundings [e.g., Afonso and Ranalli, 2004]. Consequently, the weak crust was made of two layer: an upper thin layer (WLC1) with the same composition as the lowermost crustal layer LC3, and a underlying layer (WLC2) made of a mixture of silicone Wacker BP29, corundum sand and oleic acid (100:75:5\% in weight) (Figure 1d).

[11] These crustal-mantle layers rested on a lowviscosity mixture made of silicone Wacker BP29, corundum sand and oleic acid (100:100:20\% in weight) simulating the asthenosphere and providing the isostatic support for the deforming continental lithosphere (Figure 1).

[12] Syntectonic accumulation of sediments during progressive subsidence of the rift zone was simulated in the experiments; this was achieved by filling the rift depression at regular time intervals with sieved k-feldspar powder.

\subsection{Scaling}

[13] The models were built with a geometric scale ratio of $6.7 \times 10^{-7}(1 \mathrm{~cm}$ in the experiments corresponds to $15 \mathrm{~km}$ in nature), so that we modeled $\sim 42 \mathrm{~km}$ of total extension of the uppermost $\sim 50 \mathrm{~km}$ of the continental lithosphere. Dynamickinematic similarity [Ramberg, 1981] was tested through dimensionless ratios relating gravitational, viscous and frictional stresses acting in the system [e.g., Corti et al., 2004]; this similarity condition ensured that the velocity of extension in the models $\left(\sim 10^{-4} \mathrm{~m} \mathrm{~s}^{-1}\right)$ scaled to natural values of $4-6 \mathrm{~mm}$ $\mathrm{yr}^{-1}$, a reasonable value for continental rift systems [e.g., Corti, 2008]. The total resistance of the lithosphere, scaled from models to nature, was estimated to vary between $\sim 510^{12} \mathrm{~Pa}$ m (within the preexisting weakness) and $\sim 410^{13} \mathrm{~Pa} \mathrm{~m}$ (for the strong surrounding regions; see Text $\mathrm{S} 1$ and Table S2 in the auxiliary material for details of calculations), well in the range of estimates for weak/strong natural lithospheres [see, e.g., Ranalli, 1995; Afonso and Ranalli, 2004; Corti et al., 2004, and references therein].

\section{Model Results}

[14] Model results are illustrated in sections 3.13.4, subdivided in four different groups on the 
basis of the angle of obliquity $\alpha$, from orthogonal extension $\left(\alpha=0^{\circ}\right)$ to low $\left(\alpha=15^{\circ}, 30^{\circ}\right)$, moderate $\left(\alpha=45^{\circ}\right)$ and high $\left(\alpha=60^{\circ}, 75^{\circ}\right)$ obliquity.

\subsection{Orthogonal Extension $\left(\alpha=0^{\circ}\right)$}

[15] During orthogonal rifting, extensional deformation nucleates at the strong-weak lithosphere boundaries in the early stages of the experiment giving rise to major boundary fault systems bordering a subsiding rift depression (Figures 2 and S1). The development of minor normal faults, antithetic to the major systems, gives rise to a pair of marginal grabens, delimiting a central horst. In these initial stages, all the extensional deformation is accommodated by slip on boundary and antithetic faults, whereas the floor of the rift depression (central horst) is undeformed (Figure S1).

[16] At $\sim 18 \mathrm{~mm}$ of stretching (corresponding to $\sim 25 \mathrm{~km}$ in nature), a change in deformation style occurs: extensional deformation starts to affect the rift floor with development of normal faults which form a graben structure within the central horst (Figures 2 and S1). Increasing extension leads to deepening of this graben, with an increasing amount of deformation accommodated by internal faults concomitant with a decrease of the amount of slip along boundary faults (Figure S1), such that internal faults accommodate more than $\sim 70 \%$ of

\section{Orthogonal rifting $\alpha=0^{\circ}$}

a
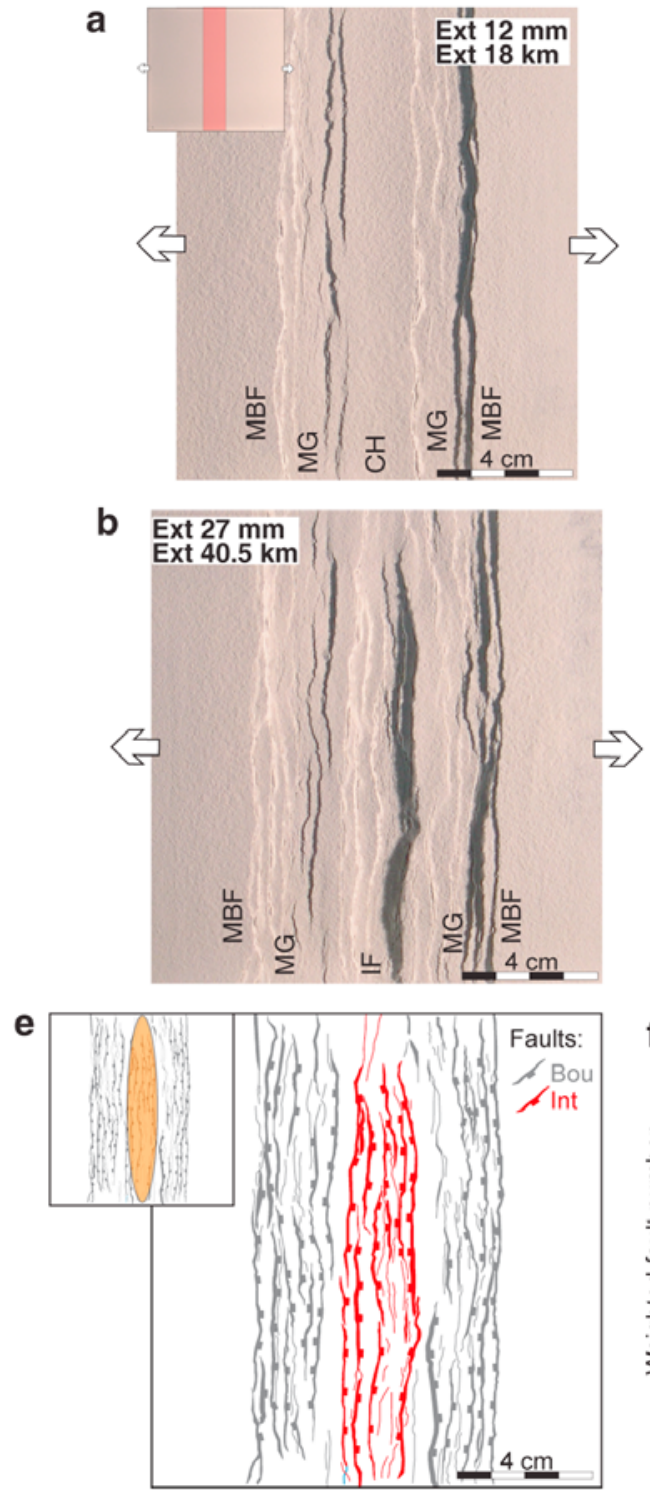
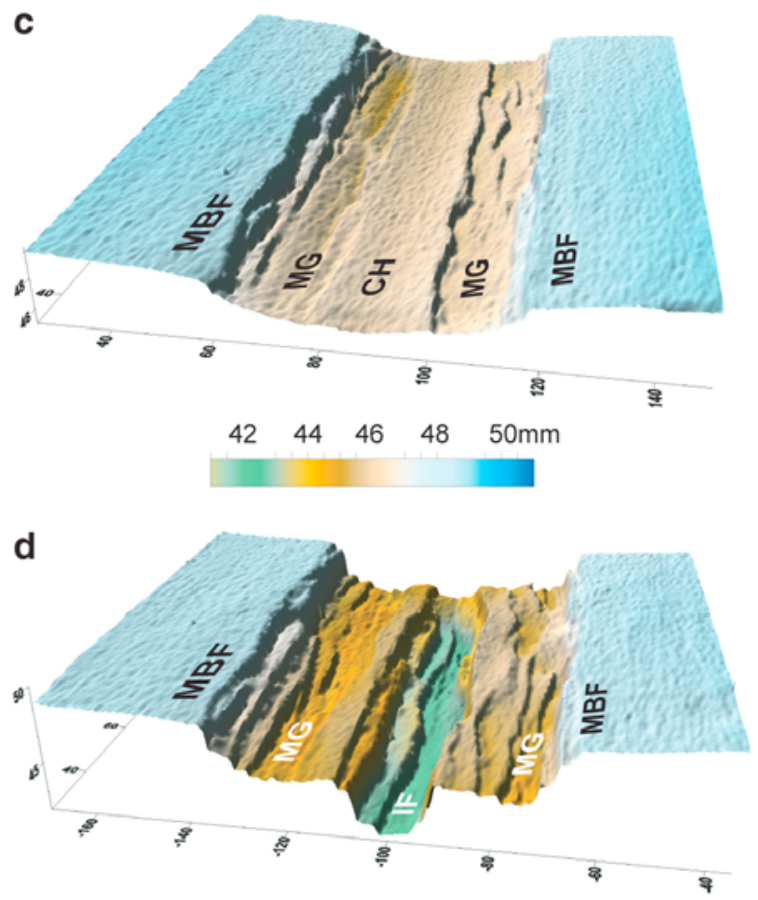

f
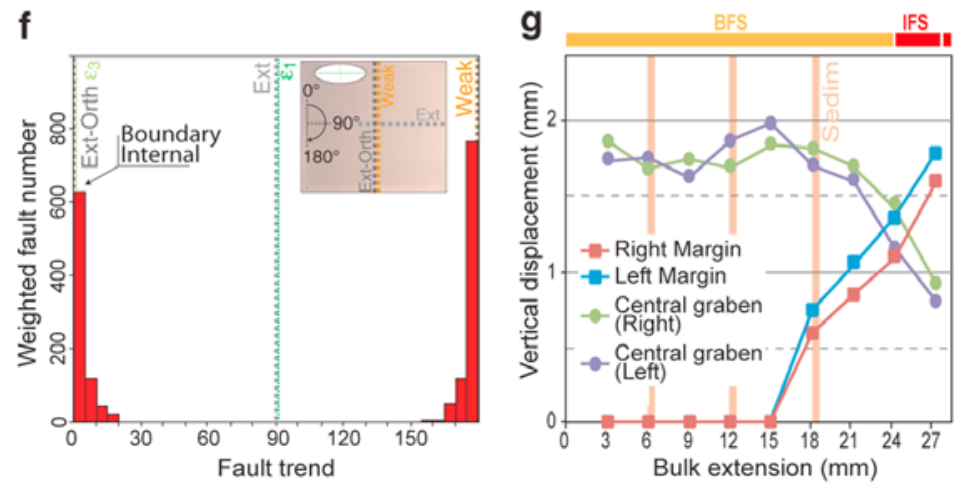

Figure 2 
the total extensional deformation at the end of the experiment $(\sim 27 \mathrm{~mm}$ of bulk extension, corresponding to $\sim 42 \mathrm{~km}$ in nature; Figure S1). We term the initial rifting phase (in which boundary fault activity dominate deformation and the rift floor is undeformed) boundary faults stage (BFS), and the later deformation stage (in which internal faults accommodate the majority of deformation and border fault activity is strongly reduced), internal faults stage (IFS; Figures 2 and S1).

[17] The final structural pattern of the model displays boundary escarpments and remnants of marginal grabens flanking a rift depression characterized by a graben-in-graben structure caused by activity of internal faults (Figures $2 \mathrm{~b}, 2 \mathrm{~d}, 2 \mathrm{e}$, and S2). The majority of normal faults are long and linear; statistical analysis suggests that these structures are parallel to the weak zone and perpendicular to the extension vector (Figure 2f).

\subsection{Low Obliquity $\left(15^{\circ} \leq \alpha \leq 30^{\circ}\right)$}

[18] In low-obliquity rift models (Figure 3), the initial stages of extension are characterized by the nucleation of 3-4 major boundary faults for each rift margin in correspondence to the strong-weak lithosphere boundaries. These are en echelon, almost linear extensional faults delimiting a sub- siding rift depression; their length tend to decrease passing from $\alpha=15^{\circ}$ to $\alpha=30^{\circ}$. As a group, these faults follow the orientation of the weak zone (i.e., the rift trend), but individually they are oblique to both the strong-weak lithosphere boundaries and the orthogonal to the extension direction (see below). Antithetic faults develop in the rift depression defining a couple of marginal grabens which delimit an undeformed rift floor. With increasing extension, the border and antithetic faults become longer and increase their vertical throw, resulting in a widening and deepening of the rift depression. Many minor faults develop inside the marginal grabens, but the floor of the central horst remains undeformed; these initial stages of extension correspond to the boundary faults stage (BFS) observed during orthogonal rifting.

[19] As for orthogonal rifting, increasing extension leads to the activation of internal faults within the previously undeformed rift depression: this occurs at $\sim 18 \mathrm{~mm}$ of stretching for $\alpha=15^{\circ}$ and at $\sim 21 \mathrm{~mm}$ of stretching for $\alpha=30^{\circ}$ (corresponding to $\sim 27$ and $\sim 32 \mathrm{~km}$ in nature, respectively; Figures $3 \mathrm{~g}$ and $3 \mathrm{n}$ ). Internal faults are normal faults striking almost perpendicular to the stretching direction; differently from the orthogonal rifting case, these faults do not define a single central graben but are arranged into two main en echelon basins (rift segments)

Figure 2. Evolution and pattern of deformation during orthogonal rifting $\left(\alpha=0^{\circ}\right)$. (a) The initial stages of rifting (amount of extension $<18 \mathrm{~mm}$ ) show the development of major boundary fault systems (MBF) that accommodate subsidence of the rift depression; together with minor antithetic faults, the boundary faults delimit two marginal grabens $(\mathrm{MG})$ that bound an undeformed central portion of the rift floor (central horst $(\mathrm{CH})$ ). (b) Increasing extension leads to a change in deformation style: extensional deformation starts to affect the central horst with development of conjugate internal normal faults (IF) delimiting a central graben. At the end of the experiment (amount of extension $\sim 27 \mathrm{~mm}$ ) the majority of deformation is accommodated by slip along the internal faults and subsidence of the central graben; although still active, the boundary faults accommodate a minor part of deformation. (c and d) Threedimensional visualization of digital elevation models of the model surface for the deformation stages illustrated in Figures $2 \mathrm{a}$ and $2 \mathrm{~b}$ (i.e., at $12 \mathrm{~mm}$ and $27 \mathrm{~mm}$ of extension). Note the marginal grabens and the undeformed central horst in Figure $2 \mathrm{c}$ and the graben-in-graben structure resulting from activation of the internal faults in Figure $2 \mathrm{~d}$. (e) Line drawing of structures at the end of the experiment (Bou, boundary faults; Int, internal faults). The small inset reports the schematic structural pattern of the model illustrating the main fault segment that accommodates extension within the rift depression (interpretation based on the extension-related thinning of the model lithosphere from analysis of longitudinal cross sections [see Corti, 2008]). (f) Fault distribution illustrated as histogram of the fault azimuths, weighted for the (tip-to-tip) fault length. The weighting factor for each fault is the ratio between the length and the minimum length of the whole data set, such that long faults have higher ratio (weight) than short ones. The frequency of the azimuth of a fault directly relates to this ratio: the longer the fault, the higher its frequency. Also reported in the graph are the direction of extension (Ext), the orthogonal to this direction (Ext-Orth), the trend of the weakness zone (Weak), and the principal strain axis $\left(\varepsilon_{1}\right.$ and $\left.\varepsilon_{3}\right)$ of the strain ellipse, calculated after Fournier and Petit [2007] for a rift-orthogonal stretching factor of $\beta \sim 2$. The small inset schematically shows these different trends, together with the strain ellipse. Fault distribution shows a main peak at $\sim 0^{\circ}$, indicating that the faults form orthogonal to the direction of extension (and to the greatest principal strain axis $\varepsilon_{1}$ ) and parallel to the weak trend (and to the smallest principal strain axis $\varepsilon_{3}$ ). (g) Graph plotting the vertical displacement accommodated by the different model domains (rift margins and central graben) versus the bulk extension (see Figure S1 for details of calculations). Note the two-phase evolution with transition from the boundary faults stage (BFS) to the internal faults stage (IFS). 


\section{Low obliquity $\alpha=15^{\circ}$}

a

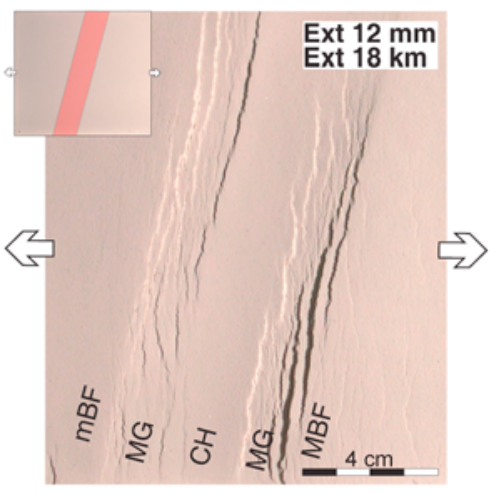

b

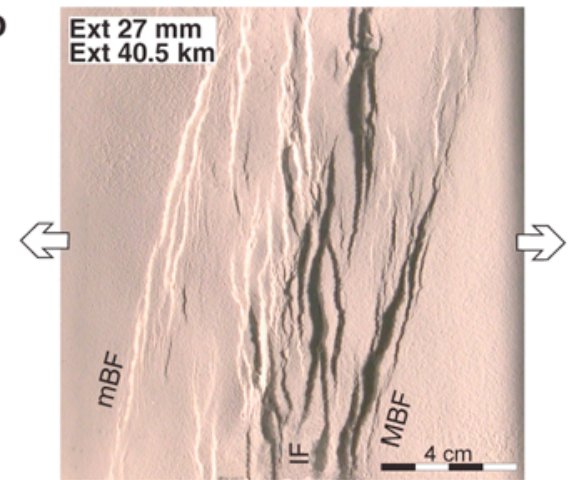

C

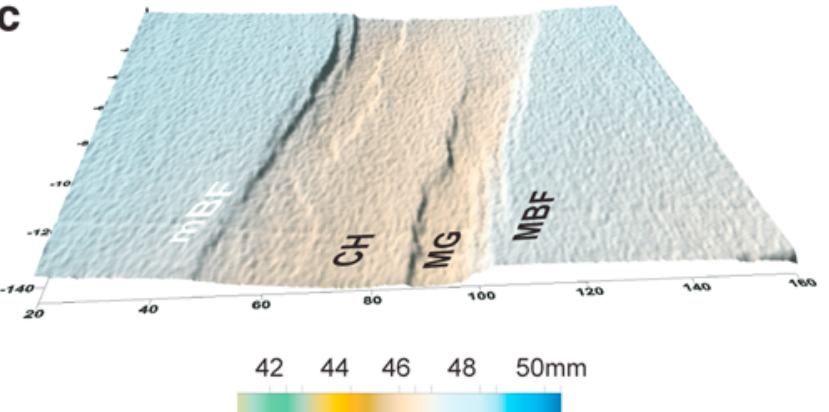

d

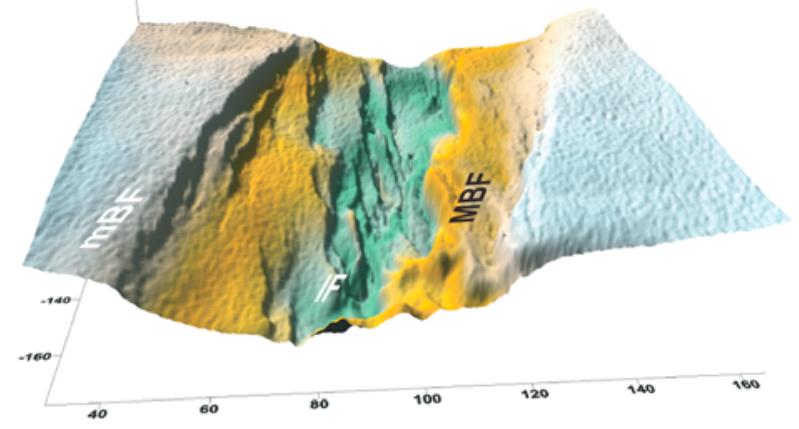

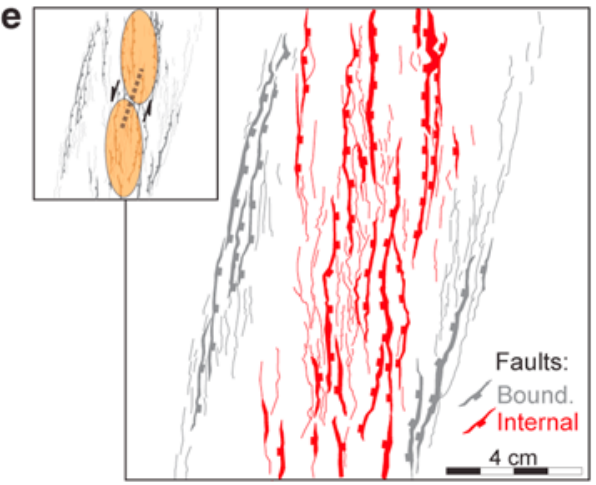

f

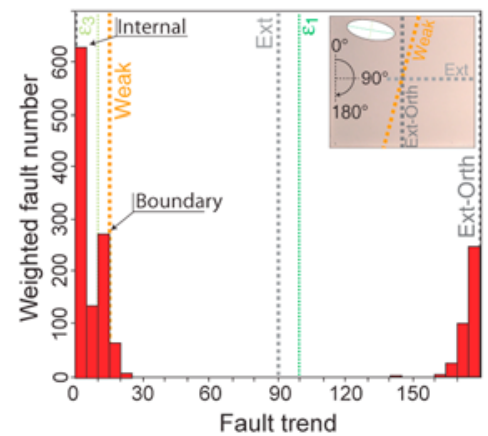

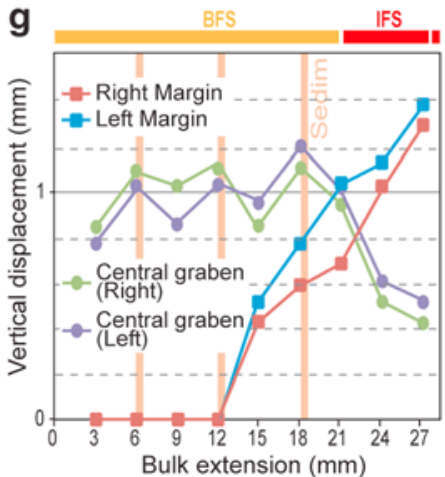

Figure 3. Evolution and pattern of deformation during low-obliquity rifting, illustrated as in Figure 2. (a-g) Model with $\alpha=15^{\circ}$ and $(\mathrm{h}-\mathrm{n})$ model with $\alpha=30^{\circ}$. Note the two-phase evolution, with transition from boundary faults stage (Figures 3a, 3c, 3h, and 3j) to the internal faults stage (Figures 3b, 3d, 3i, and 3k). Also note the en echelon arrangement of boundary faults and the clustering of internal faults into two en echelon fault segments affecting the rift depression connected by a transfer zone (see small insets in Figures $3 \mathrm{e}$ and 31 and section 3.2 for details). In Figures $3 \mathrm{f}$ and $3 \mathrm{~m}$, internal faults are characterized in both experiments by a main peak between $0^{\circ}$ and $5^{\circ}$, indicating that they are almost perpendicular to the extension direction. Boundary faults are instead slightly oblique to both the orthogonal to the extension direction and the weak zone; the angle between these faults and the weak zone (i.e., rift trend) increases with $\alpha$, as displayed by the azimuths of boundary faults that peak around $10-15^{\circ}$ for $\alpha=15^{\circ}$ and around $15-20^{\circ}$ for $\alpha=30^{\circ}$. Note that in both cases, the en echelon boundary faults are orthogonal to the greatest principal strain axis $\varepsilon_{1}$ and parallel to the smallest principal strain axis $\varepsilon_{3}$, calculated after Fournier and Petit [2007] for a rift-orthogonal stretching factor of $\beta \sim 1.9$ and $\beta \sim 1.7$ for obliquity of $15^{\circ}$ and $30^{\circ}$, respectively. In the graphs of Figures $3 \mathrm{~g}$ and $3 \mathrm{n}$, note the two-phase evolution with transition from the boundary faults stage (BFS) to the internal faults stage (IFS). 
Low obliquity $\alpha=30^{\circ}$
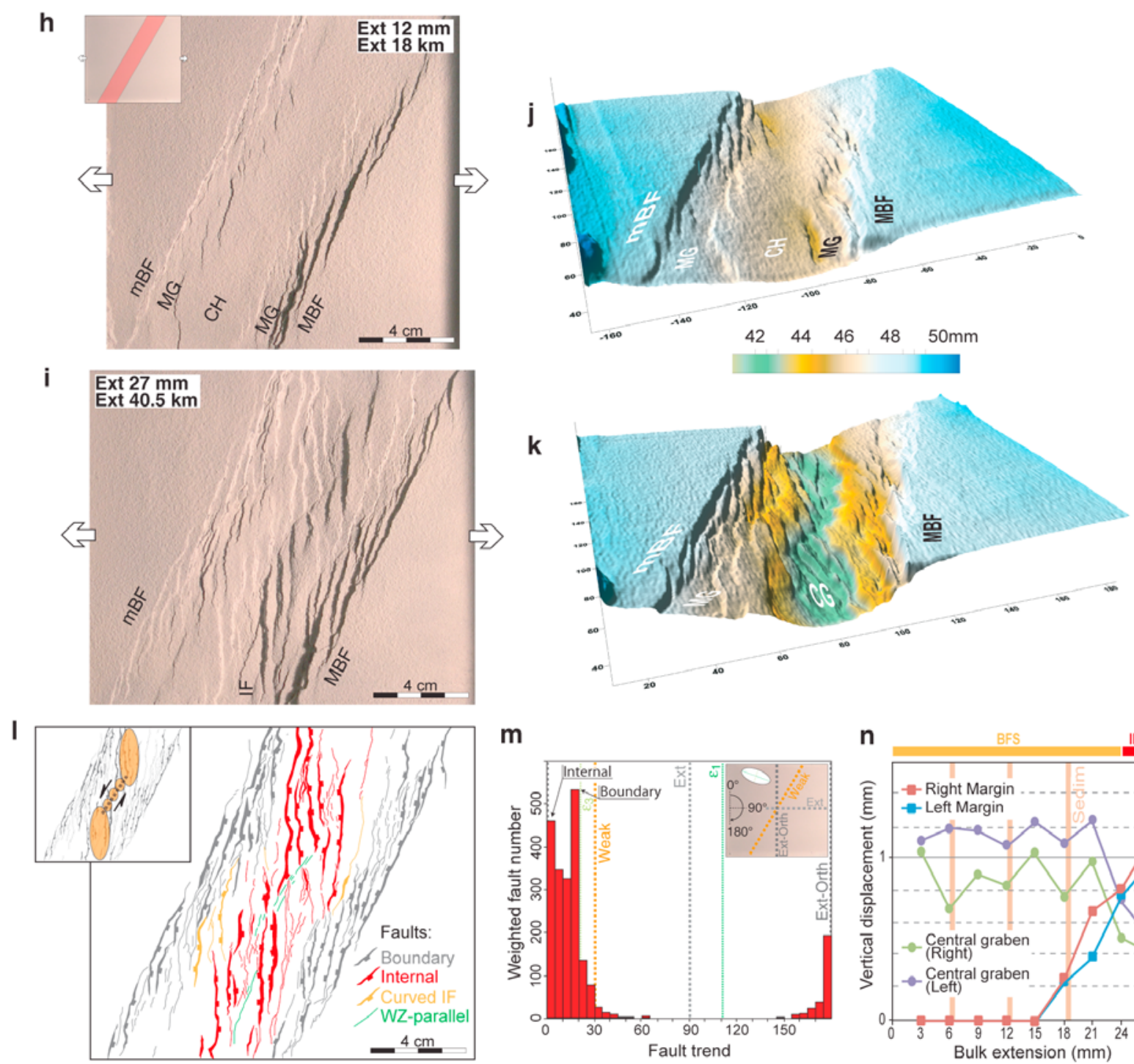

m

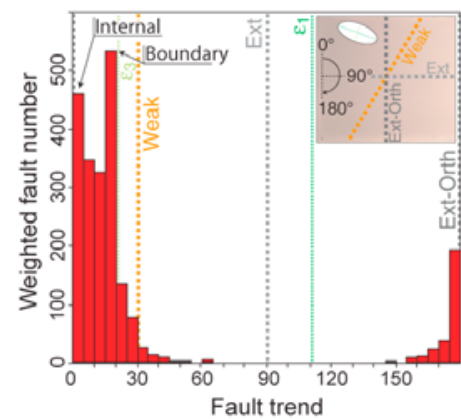

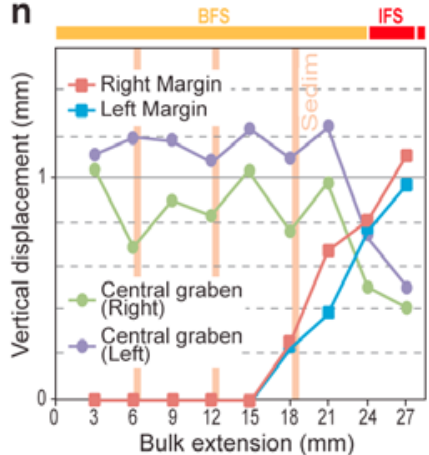

Figure 3. (continued)

connected by a complex transfer zone characterized by a significant strike-slip component of motion (Figure 3). The increase in extension leads to the deepening of the en echelon basins and increase in vertical displacement on internal faults, with consequent decrease of slip on boundary faults and transition to the internal faults stage (IFS) at $\sim 21 \mathrm{~mm}(\sim 31 \mathrm{~km})$ and $\sim 24 \mathrm{~mm}(\sim 36 \mathrm{~km})$ of bulk extension for obliquity of $15^{\circ}$ and $30^{\circ}$, respectively (Figures $3 \mathrm{~g}$ and $3 \mathrm{n}$ ). In parallel, the complexity of the transfer zone connecting the two fault segments increases and a main oblique-slip fault develop subparallel to the trend of the weakness zone (Figure 3).
[20] As observed for orthogonal rifting, at the end of the experiment internal faults accommodate the largest part of deformation ( $70-80 \%$; Figures $3 \mathrm{~g}$ and 3n). Statistical analysis of the fault pattern (Figures $3 \mathrm{f}$ and $3 \mathrm{~m}$ ) clearly highlights the two distinct fault systems: boundary and internal. The internal faults are for both experiments almost perpendicular to the extension direction (Figures $3 \mathrm{f}$ and $3 \mathrm{~m}$ ). The orientation of the en echelon boundary faults is slightly oblique to both the orthogonal to the extension direction and the weak zone (that they follow as a group), but is orthogonal to the greatest principal strain axis $\varepsilon_{1}$ (i.e., parallel to the smallest principal strain axis $\varepsilon_{3}$ ). The angle between boundary faults and the weak zone (i.e., rift trend) 
increases as $\alpha$ shifts from $15^{\circ}$ to $30^{\circ}$ (Figures $3 \mathrm{f}$ and $3 \mathrm{~m})$.

\subsection{Moderate Obliquity $\left(\alpha=45^{\circ}\right)$}

[21] As in previous experiments, few en echelon boundary faults nucleate at the boundaries between strong and weak lithosphere; again these faults follow the orientation of the weak zone as a group and individually they are oblique to both the strongweak lithosphere boundaries and the orthogonal to the extension (Figure 4). This initial deformation phase, dominated by these boundary faulting and subsidence of the rift floor, still corresponds to the boundary faults stage outlined above. However, if compared to the previous models, the deformation migrates inside the rift depression earlier during moderate obliquity: the first internal faults can be detected at $\sim 9 \mathrm{~mm}$ of stretching (corresponding to $\sim 13.5 \mathrm{~km}$ in nature) and the transition to the internal faults stage occurs at $\sim 15 \mathrm{~mm}(\sim 22.5 \mathrm{~km})$ of bulk extension (Figure 4g). As in the previous models, in this latter deformation stage the largest part of extensional deformation is accommodated by the nucleation and lengthening of internal faults; in contrast to low-obliquity models, these faults are not orthogonal to the stretching vector but strike at small angle to this direction (Figure 4). Although the surface deformation pattern is more complex than in previous models, still two main en echelon rift segments, connected by a complex transfer zone can be identified (Figure 4). An increase of extension leads to further deepening of the basins and further propagation of the internal faults that close to the rift margins gently curve and acquire an S-shaped geometry to adjust with the border fault systems (Figure 4).

[22] At the end of the experiment, the internal faults accommodate $\sim 85 \%$ of vertical displacement (Figure 4g); rift segments are characterized by a sigmoidal shape and are connected by oblique-slip faults subparallel to the weakness zone trend within the transfer zone (Figure 4). Differently to the previous experiments, statistical analysis of fault azimuths in the moderate obliquity models display three different main peaks (Figure 4f). The main peak corresponds to the internal faults that, as stated above, are oblique to the orthogonal to the extension direction; a secondary peak is related to the en echelon boundary faults, individually oblique to both the weak trend and the orthogonal to the extension but orthogonal to the greatest principal strain axis $\varepsilon_{1}$ (i.e., parallel to the smallest principal strain axis $\varepsilon_{3}$ ); the third, minor peak corresponds to the oblique-slip faults developing subparallel to the trend of the preexisting weakness (i.e., rift axis) within the transfer zone.

\subsection{High Obliquity $\left(60^{\circ} \leq \alpha \leq 75^{\circ}\right)$}

[23] Conversely to previous kinematical boundary conditions, deformation does not nucleate at the strong-weak lithosphere boundaries with development of boundary faults; rather, oblique internal faults accommodate extension since the early stages of stretching (Figure 5). These faults are characterized by a predominantly oblique-slip kinematics, which accommodates the strong strike-slip component of motion imposed by the high-obliquity rifting (Figure 5).

[24] As extension increases, the internal faults grow in length and different fault systems interact in the rift center, increasing the structural complexity of this area where rift-parallel faults with dominant strike-slip kinematics develop at $\sim 18 \mathrm{~mm}$ of stretching ( $\sim 25 \mathrm{~km}$ in nature). Boundary faults do not develop at all for $\alpha=75^{\circ}$ or develop as very minor structures in the late stages of extension for $\alpha=60^{\circ}$ experiments; as a consequence, subsidence of the rift floor is limited in these models. Overall, in contrast to the behavior shown by low- to moderate-obliquity rifting, a single internal faults stage characterizes the evolution of high-obliquity models (Figures $5 \mathrm{~g}$ and $5 \mathrm{n}$ ).

[25] At the end of the experiment, oblique-slip and strike-slip faults within the rift characterize the structural pattern; their interaction close to the rift axis gives rise to complex rhomboidal structures (Figure 5). These two distinct fault systems are indicated by two distinct peaks in the histograms of fault distribution: the main peak corresponds to the oblique-slip faults that are oblique to both the weakness zone (i.e., rift trend) and the orthogonal to the extension direction; the minor peak is instead related to the strike-slip faults, subparallel to the rift axis trend (Figures $5 \mathrm{f}$ and $5 \mathrm{~m}$ ).

\section{Discussion}

\subsection{Evolution, Pattern, and Partitioning of Deformation During Oblique Continental Rifting}

[26] The above experiments support that the response of the continental lithosphere to extension is strongly influenced by the presence of weakness 
Moderate obliquity $\alpha=45^{\circ}$
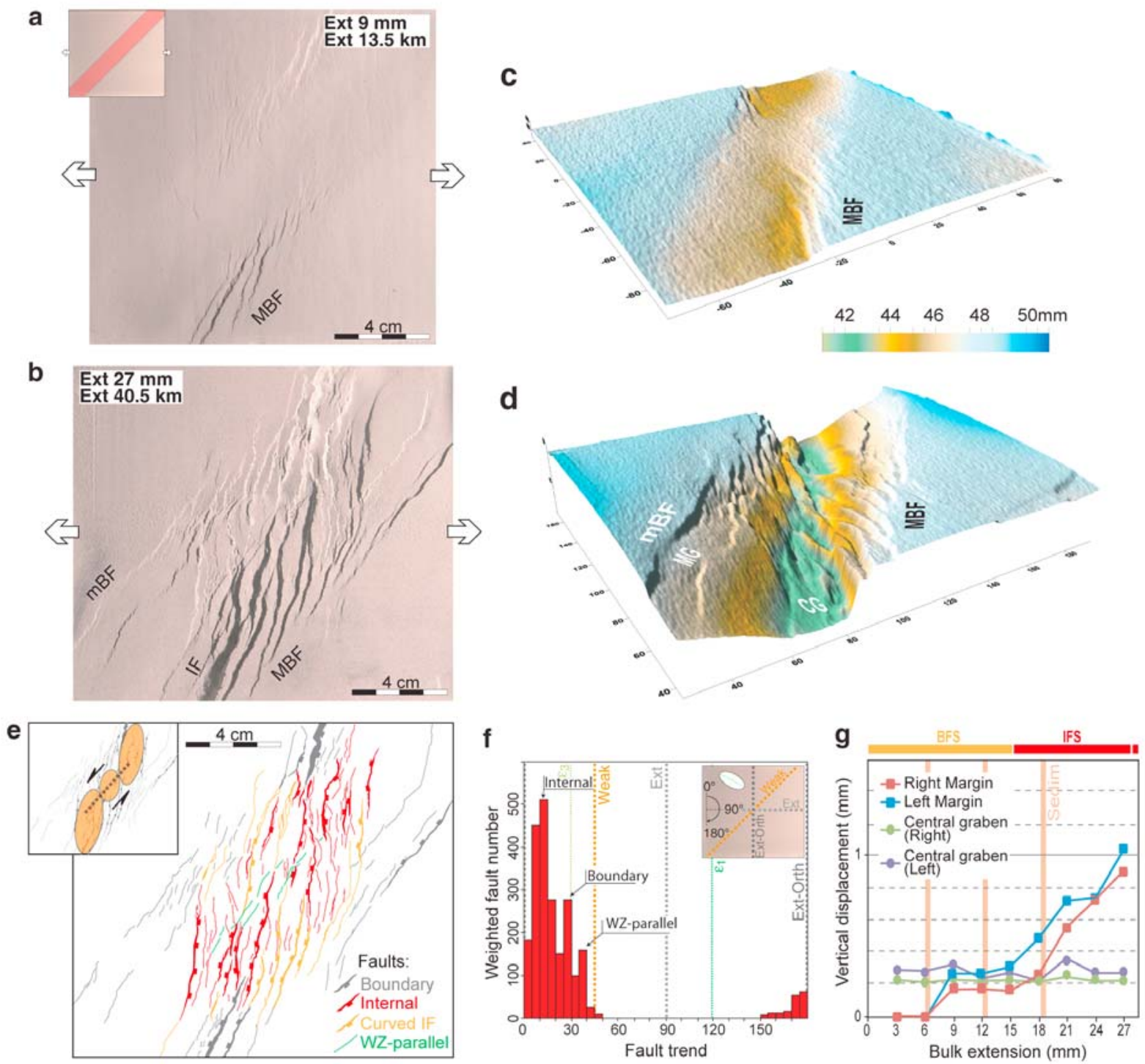

Figure 4. Evolution and pattern of deformation during moderate obliquity rifting, illustrated as in Figure 2. In Figures $4 \mathrm{~b}$ and $4 \mathrm{e}$ note that some internal faults (indicated as curved IF) gently curve close to the rift margins and acquire an S-shaped geometry to adjust with and reactivate parts of the border faults. Also note that the rift architecture is still characterized by two en echelon segments (suborthogonal to the extension direction) connected by a transfer zone (see small inset of Figure 4e). In the histogram of fault distribution note the three main peaks corresponding to the internal faults (main peak at around $10^{\circ}-15^{\circ}$ ), boundary faults (peak at $25^{\circ}-30^{\circ}$ ), and faults subparallel to the trend of the preexisting weakness (WZ-parallel; minor peak at $35^{\circ}-40^{\circ}$ ). Note that as in the previous cases, the en echelon boundary faults are orthogonal to the greatest principal strain axis $\varepsilon_{1}$ and parallel to the smallest principal strain axis $\varepsilon_{3}$, calculated after Fournier and Petit [2007] for a rift-orthogonal stretching factor of $\beta \sim$ 1.6. As in the previous models, the graph of Figure $4 \mathrm{~g}$ evidences the transition from the boundary faults stage (BFS) to the internal faults stage (IFS).

zones, inherited from previous deformation phases. Model results suggest that the evolution, pattern and partitioning of deformation are controlled by the orientation of the weakness with respect to the stretching vector, resulting in two end-member evolutions and characteristics of deformation, observed in orthogonal (and low- to moderateobliquity) rifting and high-obliquity rifting (Figure 6).

\subsubsection{Evolution of Deformation}

[27] During orthogonal and low- to moderateobliquity rifting $\left(\alpha \leq 45^{\circ}\right)$, deformation is charac- 
High obliquity $\alpha=60^{\circ}$

a

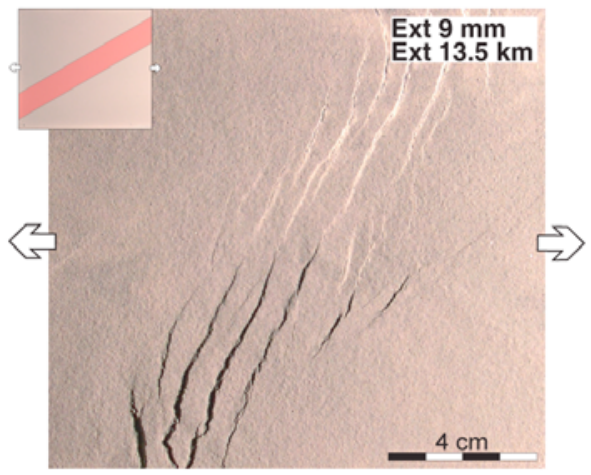

b

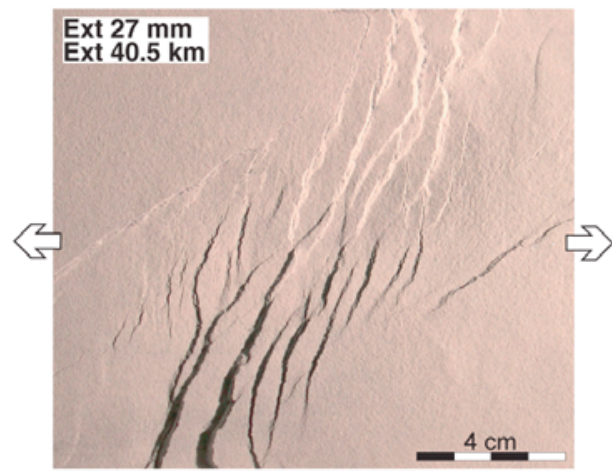

C

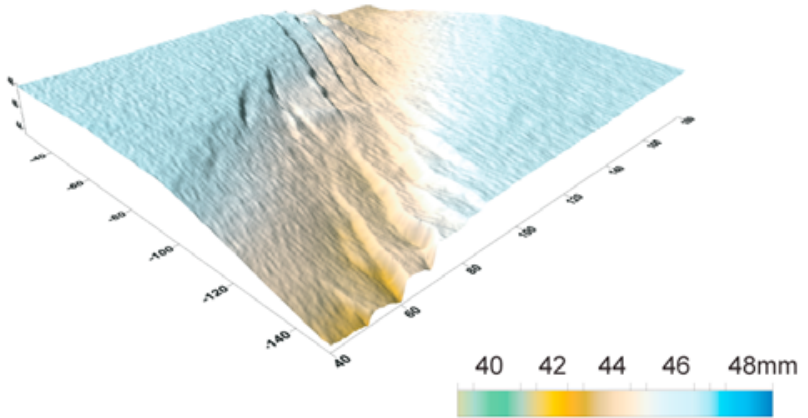

d

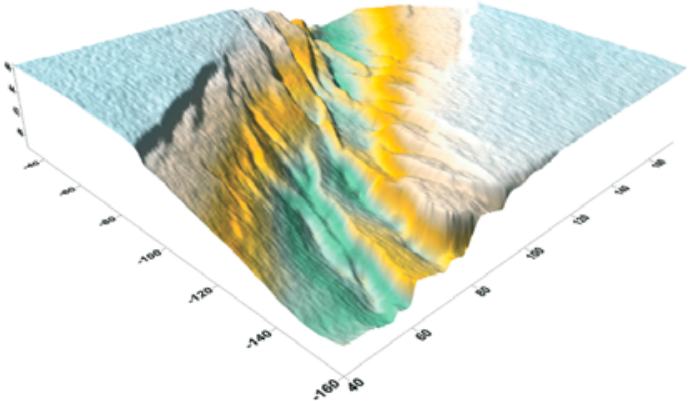

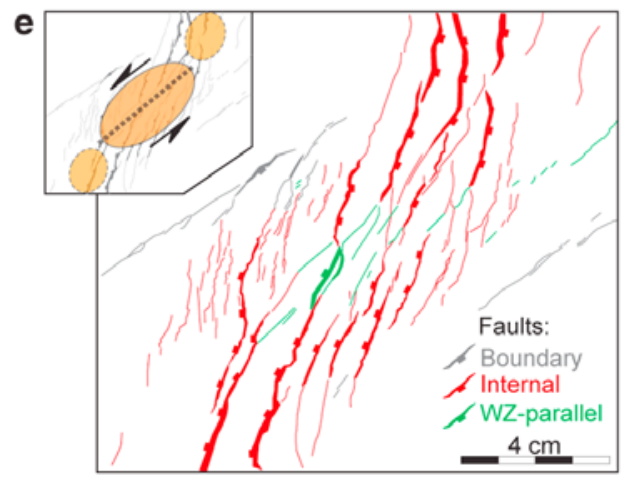
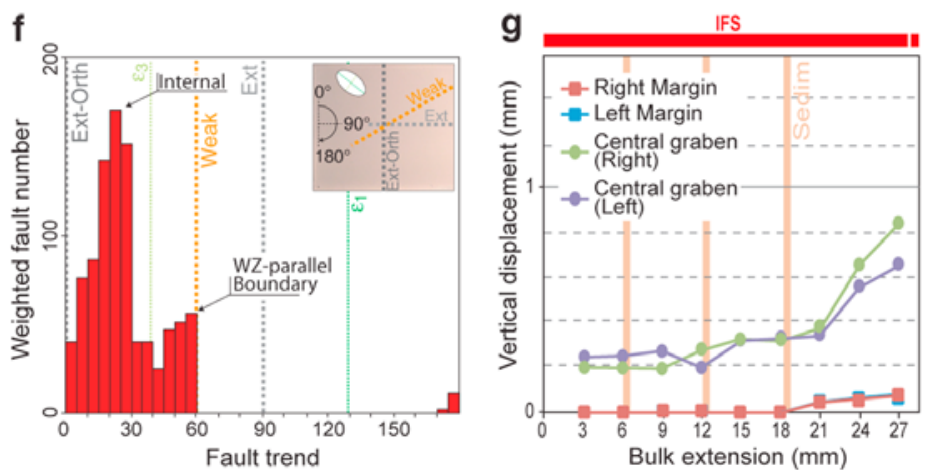

Figure 5. Evolution and pattern of deformation during high-obliquity rifting, illustrated as in Figure 2. (a-g) Model with $\alpha=60^{\circ}$ and $(\mathrm{h}-\mathrm{n})$ model with $\alpha=75^{\circ}$. Note that differently from the previous low-obliquity models, rift architecture for $\alpha>45^{\circ}$ is characterized by the (predominantly) strike-slip deformation in the model center (see small insets in Figures 5e and 51). In the histogram of fault distribution note two main peaks corresponding to the internal fault oblique to the extension direction (main peak at around $20^{\circ}-25^{\circ}$ for $\alpha=60^{\circ}$ and around $30^{\circ}-35^{\circ}$ for $\alpha=75^{\circ}$ ) and faults subparallel to the trend of the preexisting weakness (WZ-parallel; peak at around $55^{\circ}-60^{\circ}$ for $\alpha=60^{\circ}$ and around $50^{\circ}-55^{\circ}$ for $\alpha=75^{\circ}$ ). Note that the minor peak corresponding to the boundary faults $\alpha=60^{\circ}$ experiment (Figure 5f) is coincident with the WZ-parallel peak. Reported in graphs are the directions of the principal strain axis $\varepsilon_{1}$ and $\varepsilon_{3}$, calculated after Fournier and Petit [2007] for a rift-orthogonal stretching factor of $\beta \sim 1.4$ and $\beta \sim 1.2$ for obliquity of $60^{\circ}$ and $75^{\circ}$, respectively. In the graphs of Figures $5 \mathrm{~g}$ and $5 \mathrm{n}$, note the one-phase evolution characterized by faulting within the rift depression (internal faults stage (IFS)).

terized by a two-phase evolution, with activation of large boundary faults during the initial stages of rifting followed by riftward migration of faulting for increasing deformation (Figures 2-4 and 6). The initial rift phase gives rise to subsidence of the rift depression in response to strong thinning of the ductile layers in the weak zone; slip along main marginal faults, combined with the thinning of the ductile layers and down-warping of the brittle layer in the central rift zone, contributes to the total subsidence of the rift depression. From mechanical considerations, this is analogous to a necking 


\section{High obliquity $\alpha=75^{\circ}$}
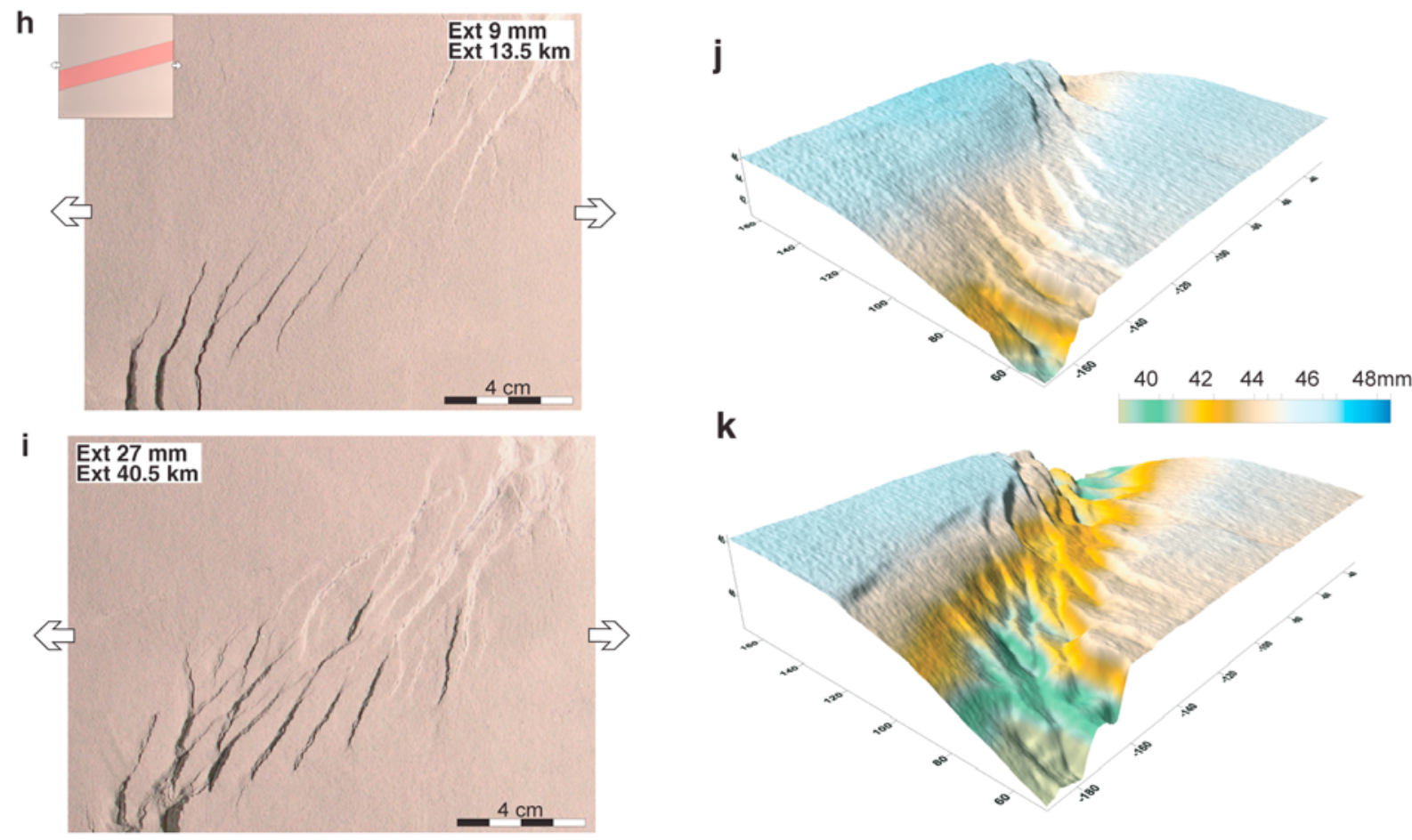

k
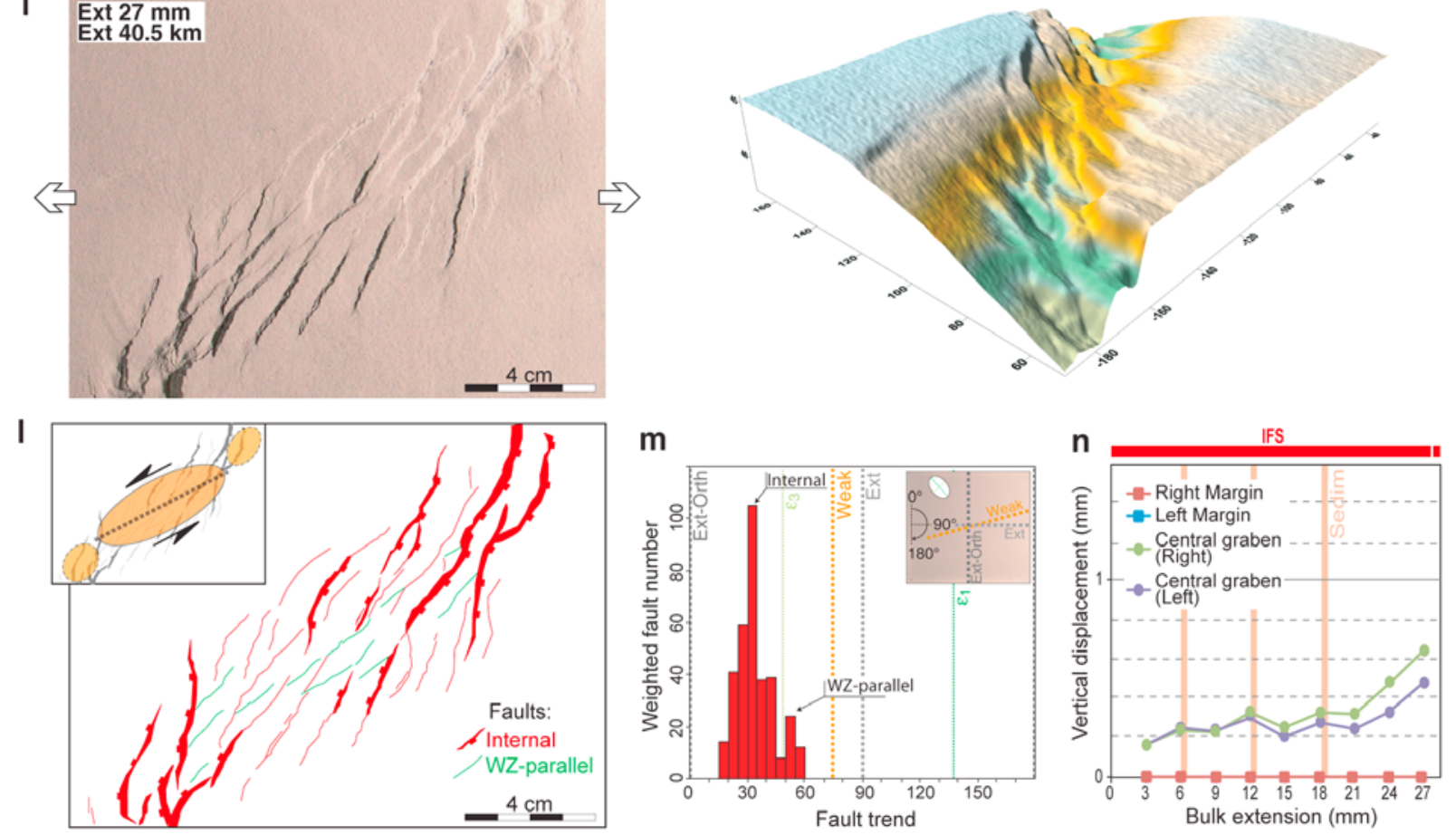

Figure 5. (continued)

instability of the lithosphere [e.g., Mulugeta and Ghebreab, 2001]. Increasing extension leads to the development of new high-angle normal faults (internal faults) in the thinnest parts of the model lithosphere (i.e., in the center of the rift depression [see Corti, 2008]); this riftward migration of deformation mimics the typical evolution of natural narrow rifts [e.g., Ziegler and Cloetingh, 2004]. For low- to moderate-obliquity rifting, this evolution corresponds to the successive activation of differently oriented fault systems under constant rift kinematics, a conclusion that greatly improves previous modeling works that resulted in a roughly contemporaneous activation of the different fault sets [e.g., Tron and Brun, 1991; Clifton and Schlische, 2001; McClay et al., 2002] (see section 4.1.4).
[28] The current models also suggest that the timing of both development of internal faults and the transition from the initial boundary faults stage to the later internal faults stage is a function of the rift obliquity and decreases increasing the angle $\alpha$ (Figure 7a). For obliquity of $45^{\circ}$ boundary fault activity is strongly reduced and deformation is soon transferred to the internal faults affecting the rift depression. This effect is emphasized for highobliquity rifting $\left(\alpha \geq 60^{\circ}\right)$, where deformation is accommodated within the rift floor (i.e., above the initial weakness) since the early stages of extension and the role of the border faults on accommodation of deformation becomes negligible. In this case, no significant changes in the spatial distribution of deformation are observed during progressive extension: in contrast to the above-discussed 


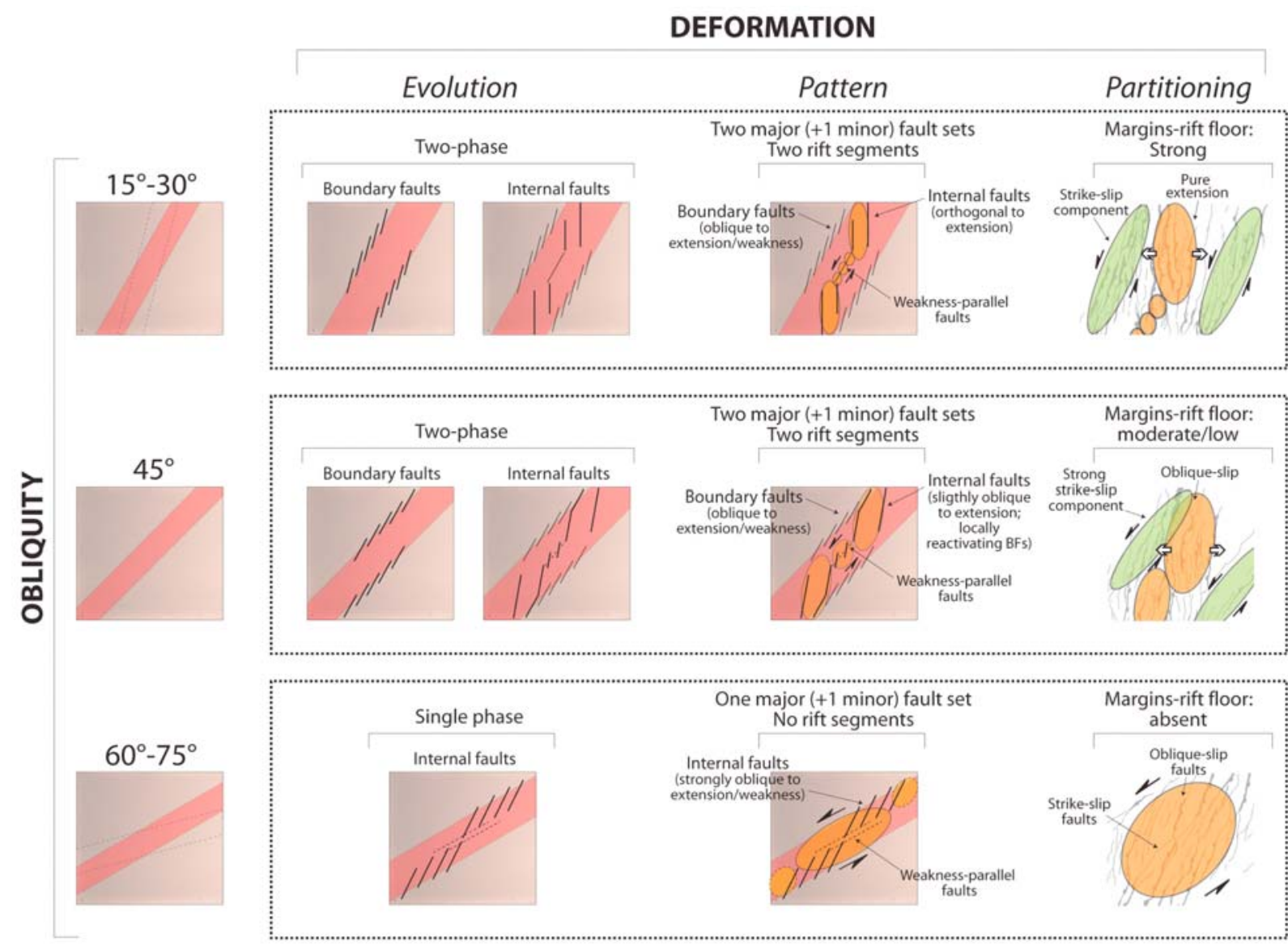

Figure 6. Summary of experimental results in terms of evolution, pattern, and partitioning of deformation as a function of rift obliquity.

models, a single phase of rifting thus characterizes high-obliquity models (Figure 7a).

\subsubsection{Pattern of Faulting}

[29] As discussed above, the current experiments show that the pattern of deformation is strongly controlled by orientation of the weak zone with respect to the stretching vector. For low-obliquity rifting, the final fault pattern is characterized by en echelon, oblique boundary faults that as a group follow the trend of the weak zone but individually are oblique to both the weak zone trend and the orthogonal to the direction of extension, and orient orthogonal to the local maximum horizontal extensional strain. Internal faults are orthogonal to far-field extension direction (Figure 3). Fault geometries show similarities with some of the previous models [Clifton et al., 2000; Clifton and Schlische, 2001; McClay et al., 2002], although in all the previous works the mean fault trends are never perpendicular to the stretching vector [see also Tron and Brun, 1991]. In the current models internal faults clustered in two en echelon segments linked by a complex transfer zone, whereas in previous models faults are more evenly distributed over the deformed zone with no development of distinct rift segments [Withjack and Jamison, 1986; Tron and Brun, 1991; Smith and Durney, 1992; Dauteuil and Brun, 1993; Clifton et al., 2000; Clifton and Schlische, 2001; McClay et al., 2002].

[30] Due to the increase in strike-slip component of deformation, in moderate obliquity models $(\alpha=$ $45^{\circ}$ ) the final fault pattern is still composed of boundary and internal faults, but geometrically more complex than in the previous low-obliquity models (Figure 4). Indeed, distinction between boundary and internal faults is less clear as internal faults, now trending slightly oblique to the orthogonal to the stretching vector, curve to reactivate the border faults approaching the margins of the depression and acquire an overall sigmoidal shape. As above, this geometry is substantially comparable to that obtained in previous models [Clifton et al., 2000; Clifton and Schlische, 2001; McClay et al., 
a

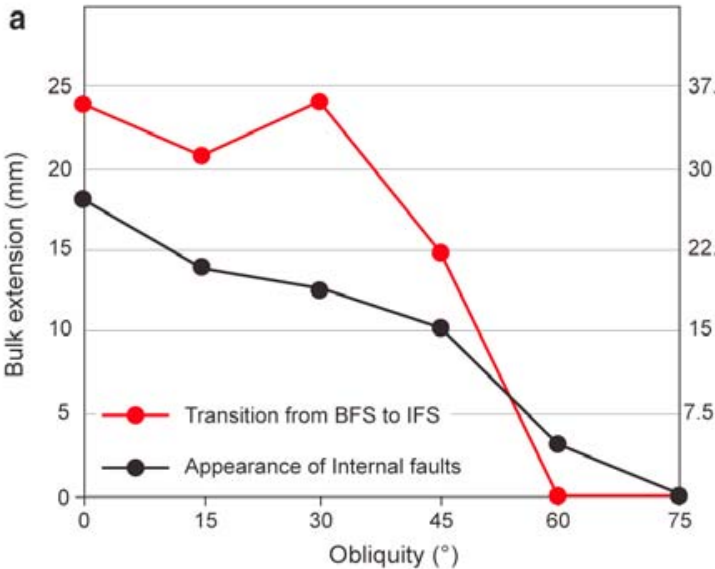

b
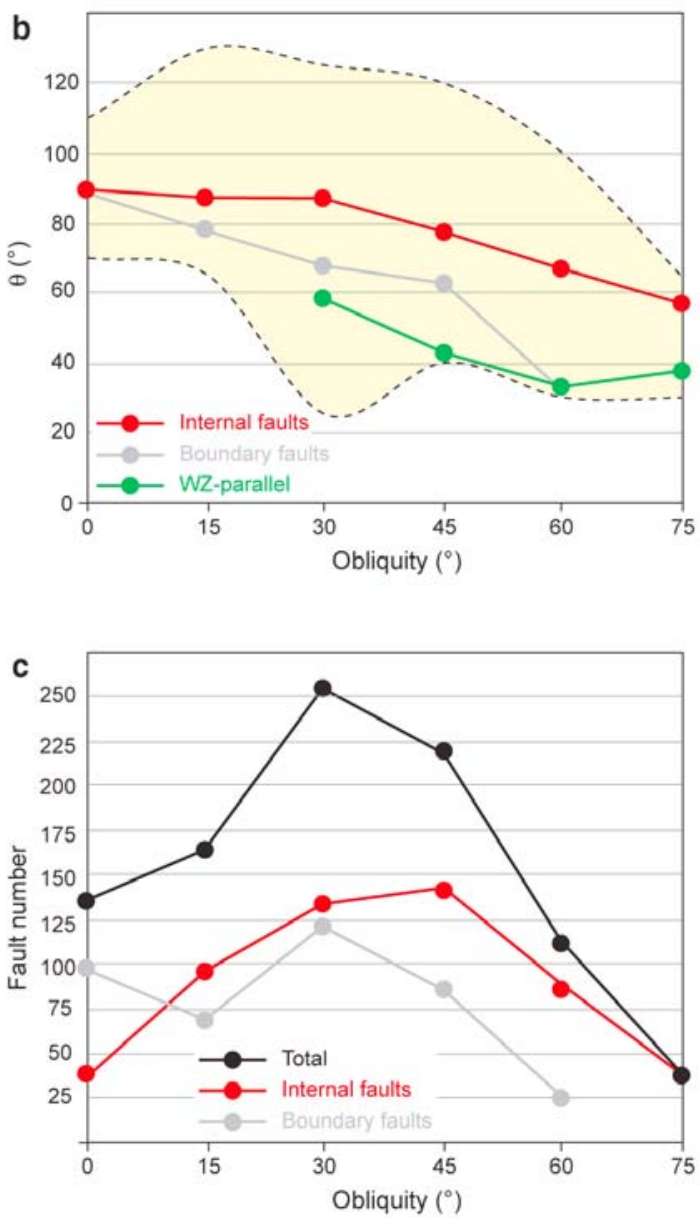
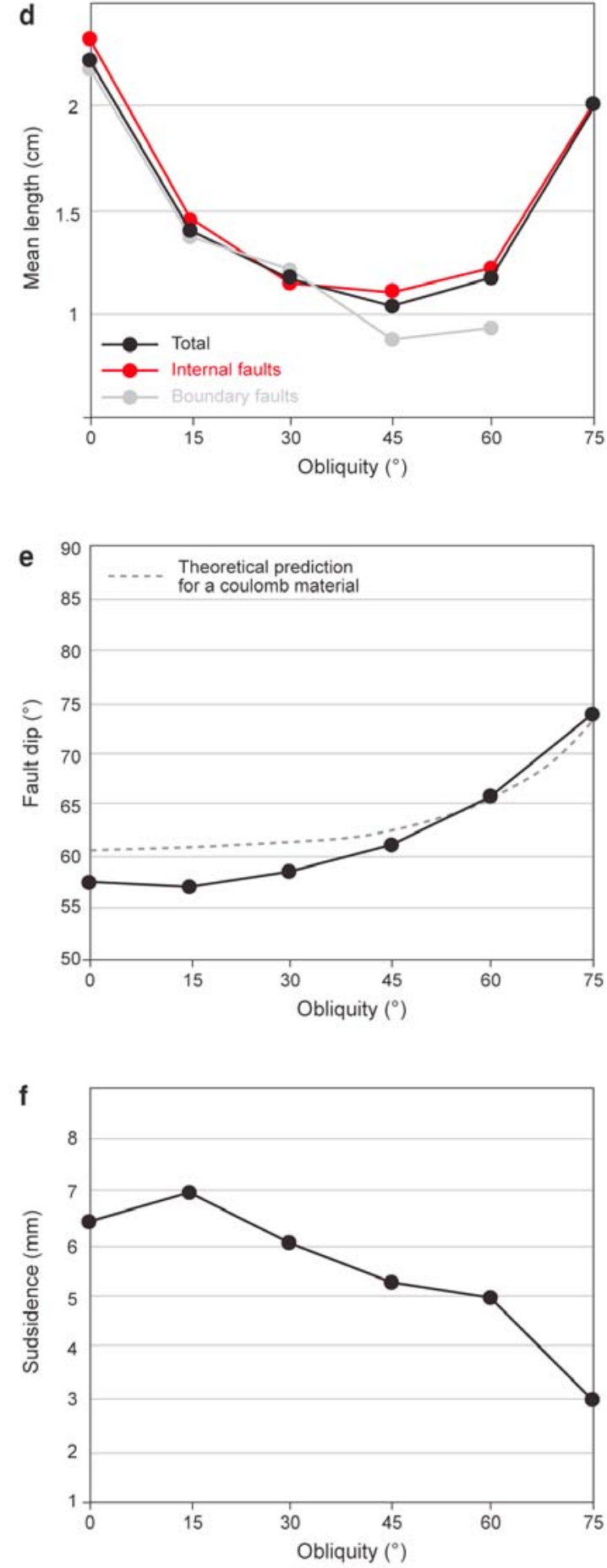

Figure 7. Graphs summarizing the variations as a function of rift obliquity $\alpha$ of different characteristics of faulting. (a) Amount of bulk extension needed for internal fault development and the transition from the boundary fault stage (BFS) to the internal fault stage (IFS). Bulk extension is calculated as mean value of three to six experiments for each obliquity angle; also reported are the values scaled to natural conditions (in $\mathrm{km}$ ). (b) The $\theta$ angle between the orientation of each fault system (defined on the basis of the peaks in the histograms of fault orientation) and the direction of extension [see Tron and Brun, 1991]. The yellowish area enclosed between dotted lines represents the total span of fault orientations displayed on histograms. (c) Fault number. (d) Mean tip-to-tip fault length. (e) Fault dip calculated from model cross sections. (f) Maximum subsidence of the rift depression calculated in the central portion of the models. 
2002], but again clustering of internal faults in distinct rift segments (connected each other by oblique-slip rift-parallel faults) differentiate the current experiments from the existing works (see section 4.1.4).

[31] In high-obliquity rifting, faults are distributed over the whole deformation region and not clustered in any clear rift segment; they accommodate the predominant strike-slip component of motion, whereas boundary faults are absent or negligible. The final pattern is characterized by internal faults oblique to the orthogonal to the extension direction and rift-parallel faults in the axial zone (Figure 5). The fault orientation is comparable to existing works [e.g., Tron and Brun, 1991; Clifton et al., 2000; Clifton and Schlische, 2001], although a more complex fault pattern (with presence of sigmoidal fault systems nearly orthogonal to extension) is observed in some of the previous models [Clifton et al., 2000; Clifton and Schlische, 2001].

[32] Comparison of different deformation characteristics as a function of $\alpha$ is summarized by the graphs of Figures $7 \mathrm{a}-7 \mathrm{e}$. These graphs show the following:

[33] 1. The angle between the orientation of the different fault systems and the direction of extension $(\theta)$ shows a general decrease increasing $\alpha$, indicating that the main fault systems tend to parallelize the direction of extension increasing obliquity [see Tron and Brun, 1991]. This conclusion is in line with previous results [e.g., Tron and Brun, 1991; Clifton et al., 2000].

[34] 2. The number of faults shows a general increase up to $\alpha$ between $30^{\circ}$ and $45^{\circ}$ and then a general decrease increasing obliquity, in a similar fashion to previous results [e.g., Tron and Brun, 1991; Clifton et al., 2000].

[35] 3. The mean fault length decreases up to $\alpha \sim$ $45^{\circ}$, then increases with obliquity; this trend fits the results by Tron and Brun [1991] but is substantially different from the experiments by Clifton et al. [2000] where a general decrease in fault length as $\alpha$ increases is observed.

[36] 4. The fault dip increases with $\alpha$, fitting the experimental results and the theoretical predictions for a Coulomb material subjected to extension with an increasing component of strike-slip deformation reported by Tron and Brun [1991].

[37] 5. The rift floor subsidence decreases increasing $\alpha$, in accord with the decrease in the extensional component of deformation (and the parallel increase in strike-slip motion) increasing obliquity.
[38] Notably, dispersion of azimuths increases increasing obliquity up to $\alpha \sim 30^{\circ}-45^{\circ}$, concomitant with a parallel increase in fault number and a decrease in mean fault length; for $\alpha>45^{\circ}$, both the dispersion of azimuths and fault number decrease, whereas the fault length increases. Again, this behavior may be explained by considering the orientation of weak zone with respect to the stretching direction, and the transition from extension- to strike-slip-dominated deformation occurring for $\alpha=$ $45^{\circ}$ (Figure S3).

[39] For $\alpha \leq 45^{\circ}$, extension dominates and the growth of major fault systems (boundary, internal) is influenced by the orientation of the weak-strong boundary with respect to the extension direction and the relative width of the rift depression (Figure S3). Boundary faults nucleate in correspondence to the weak-strong transition zone and are oblique to its trend, with obliquity increasing with $\alpha$. The growth of these structures is influenced by their orientation with respect to the weak-strong boundary: in fact, boundary faults cannot propagate neither outside the rift (where the lithosphere is too strong) nor inside the rift depression (where either basal ductile shear stresses have not grew enough to rupture the brittle crust in the early stages of extension, or deformation is accommodated by extensionorthogonal internal faults in the latest stages of stretching). As a result, for low-obliquity ( $\alpha=$ $15^{\circ}$ ) boundary faults are subparallel to the weakness and can grow long distances in this direction, whereas for $\alpha=45^{\circ}$ they are more oblique to the weakness such that their growth is limited (Figure S3). Similarly, internal faults form and grow orthogonal or suborthogonal to the direction of extension; their lateral growth is limited by the relative narrowing of the rift depression in the extension-orthogonal direction as $\alpha$ increases (Figure $\mathrm{S} 3$ ).

[40] For $\alpha>45^{\circ}$, strike-slip deformation dominates, the major fault systems form inside the weak zone but are strongly oblique to the orthogonal to the extension and consequently no more limited in their lateral growth by the width of the rift depression. In this case, few, long faults with predominant strikeslip motion accommodate deformation (Figure S3).

\subsubsection{Partition of Deformation}

[41] In low-obliquity models deformation is spatially and kinematically partitioned between the rift margins and the valley floor (Figures 6 and S4). At rift margins, the en echelon arrangement of boundary faults testify a strike-slip component of motion, resulting in an overall oblique-slip kinematics of 
fault systems; conversely, the fault swarms affecting the valley floor are characterized by a nearly dip-slip (pure extensional) kinematics, although a local complex kinematics is observed at the transfer zones connecting the fault segments. Similar patterns of strong rift margins/rift floor partitioning of deformation have not been described in previous modeling, but have been described in natural continental (e.g., Main Ethiopian Rift [see Corti, 2009]) and oceanic (e.g., Mohns Ridge [see Dauteuil and Brun, 1996] and Gulf of Aden [see Dauteuil et al., 2001]) rifts.

[42] Deformation partitioning between the rift margins and the valley floor is still observed during moderate obliquity $\left(\alpha=45^{\circ}\right)$, but is less developed than in low-obliquity models. In this case, a distinction between internal and boundary faults is, at places, less clear (see above) and internal faults are not orthogonal to the direction of extension and thus accommodate a (minor) component of strike-slip deformation (Figure 6).

[43] For high-obliquity $\left(>45^{\circ}\right)$ rifting, strain partitioning between the rift floor and the margins is not observed; deformation affects the rift floor and is kinematically accommodated by oblique-slip and strike-slip faults (Figures 6 and S4) [e.g., Tron and Brun, 1991].

\subsubsection{Discussion on Differences/ Similarities With Previous Models}

[44] As outlined above, existing analog modeling works on oblique extension mostly focused on the analysis of the influence of obliquity on the pattern of faulting of the brittle upper crust. The only previous lithospheric-scale experiments [Mart and Dauteuil, 2000] mostly focused on the largescale patterns of growth/interaction of different rift segments; these models only investigated orthogonal and low-obliquity rifting $\left(\alpha=0^{\circ}, 15^{\circ}\right.$, $30^{\circ}$ ) and adopted a simplified brittle/ductile twolayer rheology as analog of the continental lithosphere, which was pulled by using lateral metal plates generating a velocity discontinuity. Deformation was accommodated in these experiments by an en echelon pattern of propagating and interacting rift segments; the results were analyzed in terms of rift architecture resulting from (alongaxis) segment growth, linkage and transfer zones development, such that the patterns of evolution, faulting and strain partitioning at the scale of a single rift segments were not investigated in these models.
[45] As discussed in sections 4.1.1-4.1.3, the current experiments support previous findings in that the evolution, pattern and partition of deformation during oblique rifting are strongly controlled by the angle of obliquity $\alpha$, in turn controlling the relative proportion between extension and shear [e.g., Withjack and Jamison, 1986; Tron and Brun, 1991; Clifton et al., 2000; Corti et al., 2001]. Similarities with previous models are observed in the variations of fault parameters such as orientation, length and dip as a function of $\alpha$, with main changes in the deformation styles occurring for $\alpha$ $\sim 30^{\circ} / 45^{\circ}$, which marks the transition from extension- to strike-slip-dominated deformation [e.g., Withjack and Jamison, 1986; Tron and Brun, 1991; Smith and Durney, 1992; Clifton et al., 2000; Corti et al., 2001]. However, the main differences concern some of significant aspects of rifting, particularly (Figure 6) (1) the patterns of evolution of deformation (diachronous activation of different fault systems in some of the current experiments versus absence of evolution in previous works, which required a successive change in the direction of extension to obtain the abovedocumented two-phase rift evolution [e.g., Bonini et al., 1997]), (2) rift architecture (development of distinct rift segments, with major extension-orthogonal fault systems versus diffuse deformation within the rift, and predominance of oblique-extension fault trends in previous works), and (3) strain partitioning (strong margins/floor partitioning in current work versus absence of significant margins/floor partition in previous experiments).

[46] We attribute these differences to the improvements in rheological layering and boundary conditions of deformation adopted in the current experiments, which make the modeling more similar to natural process of extension of the continental lithosphere. Crustal-scale models were indeed limited by the simplified boundary conditions in terms of application of extensional stresses and rheology. Stresses were in these models applied at the base of the brittle crust through either extension of a viscous layer above a basal velocity discontinuity or a rubber sheet pulled by metal plates; the model rheological layering was simplified by using a single brittle layer (either clay or sand), lying above either a thin viscous layer used to distribute extension or directly above a rubber sheet. Basal application of stresses through a velocity discontinuity may affect the local stress orientation in a dominant way [e.g., Morley, 1999b]; the use of a basal rubber sheet may help to avoid this problem, but in both cases the absence of ductile layers and 
isostatic support provided by the asthenosphere prevent the model to properly respond to the progressive, heterogeneous thinning. The current models tried to overcome these problems by adopting a complex brittle/ductile rheology and an experimental setup in which the centrifuge forces impose a uniform stress field on the models and the distribution of deformation is controlled by lateral variations in strength and rheology due to the presence of a pervasive weakness zone, a reasonable approximation of the natural process of continental oblique extension (see section 4.2). As in nature, stresses evolve in the models in response to the progressive heterogeneous thinning of the lithosphere. For low- to moderate-obliquity rifting this results in complex patterns of evolution, architecture and partitioning of deformation illustrated above (two-phase evolution with activation of differently oriented fault systems, development of discrete rift segments with strong partition of deformation between the margins and the rift floor; Figure 6) that, although being different from previous (crustal-scale) models, are strikingly similar to both numerical models with similar boundary conditions [van Wijk, 2005; see also van Wijk and Blackman, 2007] and natural examples from continental and oceanic settings (see above) [see also Ziegler and Cloetingh, 2004]. These results fit those obtained in oblique rifting models with $\alpha=$ $30^{\circ}$ and $45^{\circ}$ and comparable boundary conditions by Corti [2008]. For high-obliquity rifting, dominance of horizontal over vertical displacement due to the predominant strike-slip deformation limits lithospheric thinning. In this case, the models do not have to respond to substantial changes in layer thicknesses, such that stresses are mainly controlled by the strike-slip displacement of the rift borders and the differences with previous crustalscale models (in terms of strain evolution and partitioning) are less significant.

\subsection{Oblique Reactivation of Lithospheric- Scale Preexisting Weaknesses and Implications for Natural Oblique Rifts}

[47] The thermomechanical process of continental rifting results from the application of extensional stresses to a predeformed, and thus already structured, anisotropic lithosphere; as a consequence, rift segments preferentially localize along preexisting weaknesses (such as ancient orogenic belts or suture zones) avoiding stronger regions (such as cratons) [e.g., Dunbar and Sawyer, 1989; Versfelt and Rosendahl, 1989; Morley, 1999a; Tommasi and Vauchez, 2001; Corti et al., 2003; Ziegler and Cloetingh, 2004]. Many structural, geophysical and experimental studies have suggested that reactivation of preexisting structures may strongly influence the way the continental lithosphere respond to extension and play an important role in controlling the evolution and the architecture of rift systems [e.g., Ziegler and Cloetingh, 2004]. The current experimental findings support these observations and evidence two end-members behaviors in terms of evolution, pattern and partition of extensional deformation that result from the different orientation of the weakness with respect to the stretching vector, and from the potential of the strength contrast between the weak-strong lithosphere at its boundaries to be reactivated during extension (Figure 8).

[48] In particular, during orthogonal and low- to moderate-obliquity rifting $\left(\alpha \leq 45^{\circ}\right)$, deformation is strongly influenced by the strong rheological contrast at the margins of the weak zone where the velocity discontinuity between the strong and weak lithosphere produces differential thinning between the strong and weak ductile lithosphere and hence induces high shear stresses at the base of the brittle crust (Figure 8). As a consequence, boundary faults develop above the rheological interface once the frictional resistance of the brittle layer is overcome. In orthogonal rifting models, these normal faults are perpendicular to extension, whereas in lowobliquity models deformation in the upper crust responds both to the far-field extension vector and the local stress reorientation imposed by the obliquity of the weak zone, resulting in en echelon arranged boundary faults characterized by an oblique slip displacement. The brittle crust within the subsiding rift depression is undeformed during these initial stages of rifting. The thinning of the ductile layers above the uprising asthenosphere occurs by strong outward flow that accumulates shear stresses at the base of the brittle crust below the rift depression (Figure 8). During progressive extension, strain rates locally increase in the center of the depression as a consequence of concentration of deformation in the ductile layer, a process aided by the predefined central increase in thickness of the weak crust; this leads to an increase in shear stresses acting at the base of the brittle crust. Although sedimentation acts to (locally) increase the thickness and strength of the brittle crust, the increasing basal shear stresses eventually overcome the frictional resistance, leading to the rupture of the model brittle crust (Figure 8) [see also Corti, 2008]. At this stage, faulting migrates inward with the development of new high-angle 

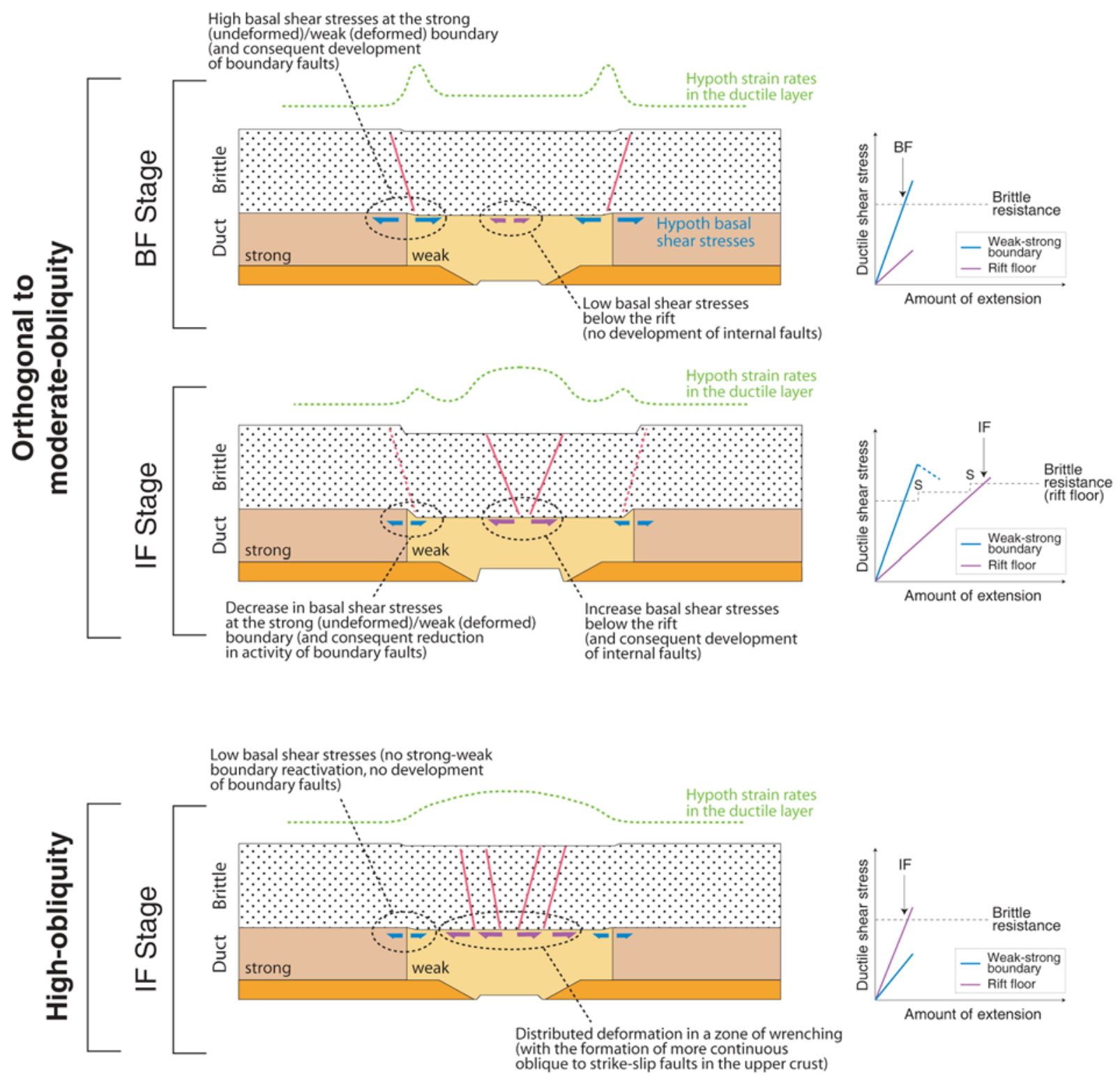

Figure 8. (left) Dynamical explanation for the end-member behaviors of the evolution of extensional deformation based on detailed analysis of model results. Reported in the drawing are the hypothesized strain rates in the ductile layer and the shear stresses acting at the base of the brittle crust in different portions of the model. Variations in local strain rates can be measured by mapping local variations in the thinning factor (see Figure S2): increase in thinning corresponds to increase in local strain rate, and vice versa; in turn, strain rates are proportional to the shear stresses acting at the base of the brittle crust [e.g., Corti et al., 2004]. (right) The hypothesized variations in ductile shear stresses at the strong-weak boundary and below the rift depression responsible for the observed evolution of faulting are reported as a function of bulk extension. BF, development of boundary faults; IF, development of internal faults; $\mathrm{S}$, increase in brittle resistance due to accumulation of synrift sediments. See section 4.2 for further details.

normal faults in the rift depression and activity on boundary faults decreases. Since the rift depression is homogenous (no rheological contrasts exist), the internal faults can form orthogonal (or suborthogonal) to the regional extension vector, resulting in the successive activation of differently oriented fault systems under constant rift kinematics. The accommodation of deformation by boundary and internal faults testifies a strain partitioning between the rift margins and rift floor, as illustrated in section 4.1.3. Model result predict that, for the adopted boundary conditions, a bulk extension of $\sim 35 \mathrm{~km}$ (i.e., $\sim 7 \mathrm{Myr}$ of extension for a velocity of $\sim 5 \mathrm{~mm} / \mathrm{yr}$ ) is needed to activate internal faults in orthogonal and low-obliquity rifting (Figure 7a). For obliquity of $45^{\circ}$, boundary fault activity is 
strongly reduced and a bulk extension of $\sim 20 \mathrm{~km}$ (i.e., $\sim 4$ Myr of extension) is needed to activate internal faults (Figure 7a).

[49] This two-phase evolution is not observed in high-obliquity rifting, where the weak-strong rheological boundary tends to parallelize the extension direction and the extensional component and vertical displacements across it are strongly reduced as the strike-slip component dominates. In these conditions, the weak-strong boundary is no more able to localize extensional deformation, shear stresses are not high enough to overcome the frictional resistance of the upper crust and boundary faults do not form (Figure 8), reducing rift evolution to a single phase in which extensional deformation is accommodated by a complex fault arrangement within the rift floor (Figure 6). The weak zone becomes indeed a distributed zone of wrenching that controls the formation of more continuous oblique to strike-slip faults in the upper crust, with no partitioning between the rift floor and margins (see sections 4.1.2 and 4.1.3).

\subsubsection{Assumptions and Limitations of the Modeling Approach}

[50] The setup of the current centrifuge models necessarily imply a simplification of the complexities of the natural process; thus, when applying the model findings to natural oblique rifts some important assumptions related to the experimental approach have to be borne in mind. The above results are indeed dependent on the adopted model setup and different starting boundary conditions (e.g., geometry of the weak zone, strength contrast, amount of synrift sedimentation, etc.) may influence the evolution of the system. We have tested simpler geometrical boundary conditions (such as a flat Moho in weak area) and the cases of absent or increased synrift sediment accumulation and found no major differences in the fault pattern and rift architecture resulting from oblique rifting (see Figure S5). We did not test more complex initial geometries of the weak zone (e.g., gradual lateral change in rheology and strength instead of a sharp, vertical rheological boundary) and future experimental work is needed to explore the influence of these parameters on oblique rifting. However, the adopted initial boundary conditions follow a wellestablished approach tested in several previous analog [e.g., Sokoutis et al., 2007, and references therein] and numerical [e.g., van Wijk, 2005] models that has been proven to represent a reasonable approximation of the natural continental rift- ing process and thus able to provide valuable insights into the process of extension in relation to preexisting weaknesses. The similarity in evolution and rift architecture with different natural examples (see below) supports that the first-order results in terms of evolution, pattern and partitioning of deformation have general relevance and applicability. Thus, oblique reactivation of preexisting lithospheric weaknesses may be a major parameter in controlling the characteristics of natural oblique rifts, not only in terms of fault pattern as outlined by previous experiments but also in evolution and strain partitioning. Complex patterns and timings of deformation may result from simple rift (and plate) kinematics, thus complicating the interpretation of geological data from natural oblique rifts as in case of low to moderate obliquity, where the diachronous activation of differently oriented fault systems may result from a constant plate motion, as exemplified below.

\subsubsection{Selected Natural Examples}

[51] The Main Ethiopian Rift is a key sector of the East African Rift System that records all the different stages of rift evolution from rift initiation to breakup and embryonic oceanic spreading [e.g., Ebinger, 2005], marking the incipient boundary between Nubia and Somalia plates (Figures 9a-9c). Thanks to these ideal conditions, knowledge on the crustal and lithospheric structure of the Main Ethiopian Rift has increased significantly in recent years as a result of the large amount of seismic, gravity, seismicity, geodetic, magnetotelluric and geochemical data collected by the Ethiopian Broadband Experiment and the EAGLE (Ethiopia-Afar Geoscientific Lithospheric Experiment) projects (see Corti [2009] for a review). These data clarified the relations between extensional deformation and the prerift lithospheric structure, highlighting that rift localization was controlled a NE-SW trending lithospheric-scale preexisting weakness zone [Bastow et al., 2005, 2008; Corti, 2008; Keranen and Klemperer, 2008; Keranen et al., 2009] represented by a suture zone separating two distinct Proterozoic basement terranes underlying the Ethiopian and Somalian plateaus [Keranen and Klemperer, 2008]. Channeling and ponding of hot plume material beneath this suture zone likely contributed to thermal weakening of the area of the future rift [Ebinger and Sleep, 1998]. Overall, the presence of this preexisting weakness created a strong, sharp lateral strength contrast with respect to the surrounding "normal" lithosphere; recent analyses [Keranen et al., 2009] indicate that this 
strength contrast may have exerted the primary control on the evolution of extension in this continental rift. Miocene-recent extension in the Main Ethiopian Rift gave rise to two sets of differently oriented faults (Figures $9 \mathrm{a}-9 \mathrm{c}$ ): a system of $\mathrm{N} 30^{\circ}-$ $45^{\circ}$ boundary faults and a set of $\mathrm{N}^{\circ}-15^{\circ}$ normal faults (see Corti [2009] for a review). These latter faults form the Wonji Fault Belt, a system of en echelon, sigmoidal fault segments obliquely affect- ing the rift depression (Figures 9a-9c). These different fault systems diachronously developed during extension: boundary faults formed in the late Miocene and accommodated basin subsidence during the Pliocene; Wonji faults developed during the Late Pliocene or Early Pleistocene in the northern sector of the rift and probably later in the central rift segment, causing a migration of deformation to the rift floor (Figures 9a-9c) [e.g.,

a

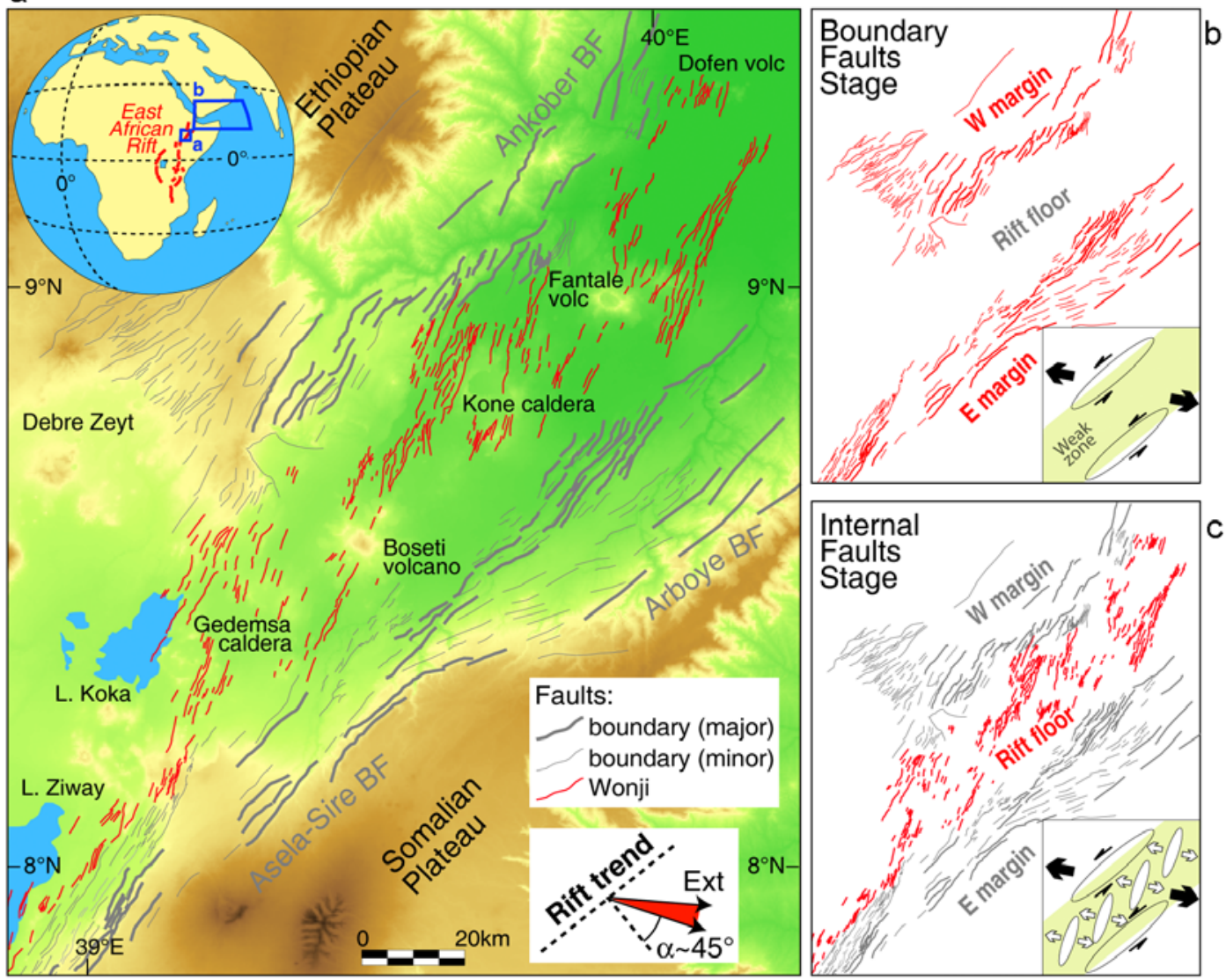

d
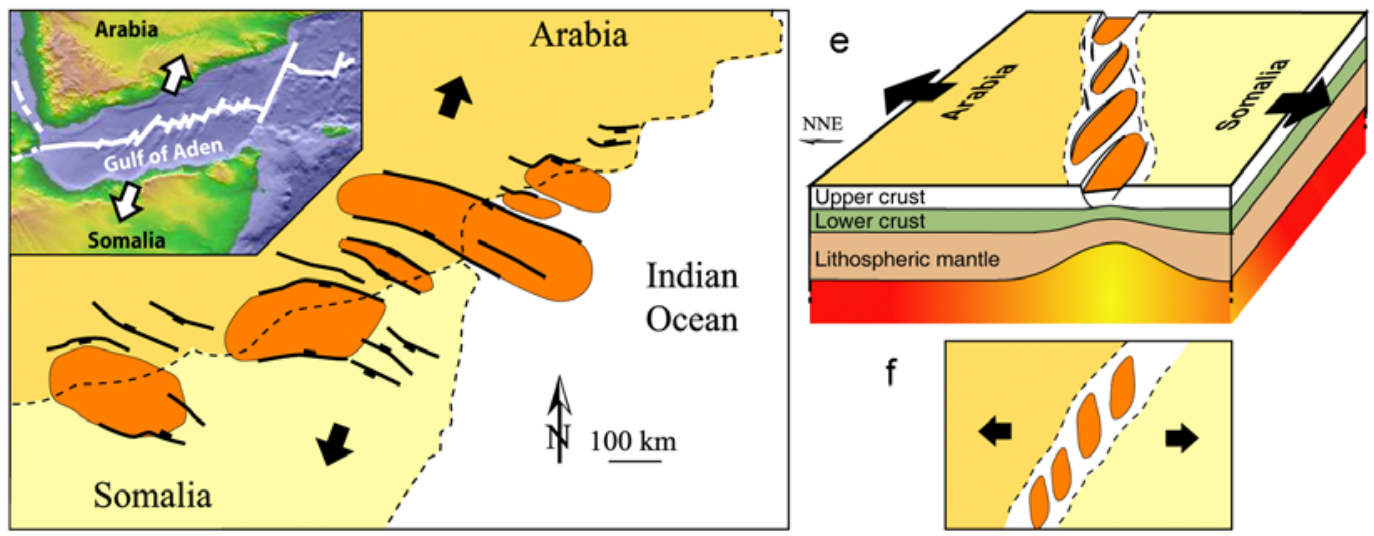

Figure 9 
Corti, 2009]. Complex models invoking a change in rift (and plate) kinematics [e.g., Bonini et al., 1997; Boccaletti et al., 1998] or plate weakening due to magmatic processes [e.g., Kendall et al., 2005; Ebinger, 2005] have been applied to explain the two-phase rift evolution and the migration of deformation during the Quaternary. The current modeling results suggest that a simple tectonic scenario may account for such a complex fault evolution and architecture [e.g., Corti, 2008]. Comparison of model evolution and fault pattern suggests indeed that the diachronous development of boundary faults and Wonji Fault Belt may have resulted from a constant Late Miocene recent $\sim \mathrm{N} 100^{\circ}$ directed extension phase [Corti, 2008], giving rise to rift obliquity of $\sim 30^{\circ}$ (central sector) to $\sim 45^{\circ}$ (northern sector) as outlined by both geological and geodetical/plate kinematics data (Figures 9a-9c) [see Corti, 2009]. Extrapolation of model results suggests that the initial MioPliocene deformation localized along areas of strong rheological contrast between the preexisting weak zone and the strong lithosphere underlying the surrounding plateaus, giving rise to large boundary fault systems bordering the subsiding, largely underfomed rift depression. Prolonged extension and thinning of the lithosphere below the rift led to the activation of the en echelon Wonji Fault Belt and the riftward migration of deformation observed during the Late Pliocene or Early Pleistocene in the northern sector, whereas fault characteristics in the central sector point to a later development of the Wonji faults that are still in a less advanced evolutionary stage [e.g., Corti, 2009]. In the northern Main Ethiopian Rift migration occurred after $\sim 20 \mathrm{~km}$ of bulk extension [e.g., Corti, 2008], fitting the predictions based on mod- eling results with $\alpha=45^{\circ}$ (see Figure 7a). Similarly, later activation and the less advanced stage of development of Wonji faults in the central sector (where obliquity is lower, $\alpha=30^{\circ}$ ) point to a higher amount of bulk extension needed to activate internal faults, again fitting modeling predictions (Figure 7a) and further supporting that, together with other parameters (e.g., crustal/lithospheric thickness, along-axis propagation of deformation, etc.), rift obliquity may strongly control the timing of evolution of deformation. Overall, in agreement with previous findings [Corti, 2008], this analysis suggests that the oblique reactivation of a lithospheric-scale inherited weakness may have controlled the two-phase rift evolution and the resulting Quaternary volcano-tectonic segmentation in the Main Ethiopian Rift.

[52] Similarly, the Gulf of Aden has been interpreted as a typical example of oblique rift with moderate obliquity where extension has progressed to continental breakup and creation of an oblique spreading center within an oceanic basin separating the Arabian and Somalian plates (Figures 9d-9f) [e.g., Dauteuil et al., 2001]. Consistent with the modeling results, thinning during the continental stage of extension has created an en echelon system of basins within an oblique rift valley (Figures 9d-9f); extensional deformation has been accommodated by three distinct fault systems, with orientations (1) subperpendicular to the plate divergence, (2) intermediate between the rift axis and normal to the divergence, and (3) parallel to the rift axis [Bellahsen et al., 2006]. Similar fault patterns have been observed in the current low- to moderateobliquity models (see Figures 3 and 4), with obliquity values $\left(30^{\circ}<\alpha<45^{\circ}\right)$ matching those resulting from the Arabia-Somalia separation [Bellahsen et

Figure 9. Exemplificative natural examples of oblique rifting. (a) Simplified structural map of the northern sector of the Main Ethiopian Rift, East Africa, showing the fault pattern resulting from the oblique rifting kinematics between Nubia and Somalia plates (modified after Corti [2008]). Faults are superimposed on a Shuttle Radar Topography Mission digital elevation model. The distribution of both boundary and Wonji faults (gray and red lines, respectively) in this northern sector of the rift fits the analog model with $45^{\circ}$ of obliquity (compare with Figure 4; see also details given by Corti [2008]); a similar obliquity angle results from the stretching vector measured from geodetic data (see inset). ( $b$ and c) The similarity between model and nature is also related to the evolution of deformation: in both cases, a first phase of boundary faults development (at the strong-weak lithosphere boundary), basin subsidence, and no deformation of the rift floor (boundary faults stage) is followed by activation of en echelon faults obliquely cutting the rift depression, strongly reducing the slip on boundary fault systems (internal faults stage). Note that inward migration of faulting occurred after $\sim 20 \mathrm{~km}$ of bulk extension, fitting the predictions based on modeling results (see Figure 7a). BF, boundary fault. (d) En echelon arrangement of Oligocene sedimentary basins in the Gulf of Aden region resulting from a hypothesized oblique continental rifting between Arabia and Somalia plates (modified from Bellahsen et al. [2006]). Inset shows the system of oblique spreading centers in the Gulf of Aden (location indicated in Figure 9a). Also shown are (e) the model for the lithospheric evolution resulting from oblique rifting and (f) a schematic top view representation of en echelon basins, rift valley trend, and direction of extension, rotated and reflected to fit the setup of the analog models presented in this paper. 
al., 2006]. Thus, although other additional parameters (e.g., reactivation of discrete fabrics, stress rotation in the latest stages of rifting) may complicate the deformation pattern of the Gulf of Aden region [e.g., Bellahsen et al., 2006], the overall deformation evolution and architecture of lithospheric thinning are strikingly comparable to the current modeling results. Notably, the current modeling results also fit the deformation pattern and partitioning of the resulting oblique spreading centers, where faults inside the axial valley have a sigmoidal shape (with a central part perpendicular to the spreading direction and tips parallel to the walls of the axial valley) and accommodate a pure extension, whereas faults on the valley walls display a right-lateral en echelon pattern and accommodate a strike-slip component of motion [Dauteuil et al., 2001].

[53] Overall, the model results may have a general relevance for other oblique rifts worldwide (e.g., Gulf of California, Viking Graben in the North Sea), where fault patterns similar to those observed in oblique models have been described [Withjack and Jamison, 1986; Brun and Tron, 1993], and may have experienced similar evolutions of deformation driven by oblique rifting kinematics. Model findings may also be applicable to other oceanic spreading ridges undergoing oblique extension (e.g., Reykjanes and Mohns ridges in the North Atlantic), where patterns of faulting, lithospheric thinning and strain partitioning similar to the current experiments have been described [see Dauteuil and Brun, 1993, 1996; Corti et al., 2001; Clifton and Schlische, 2003; van Wijk and Blackman, 2007].

\section{Conclusions}

[54] The current centrifuge models have improved existing experimental studies of oblique rifting by considering a complex brittle-ductile lithospheric multilayering, and more realistic boundary conditions in terms of application of extensional stresses. These improvements have resulted in more complex scenarios of deformation, which suggest that the oblique reactivation of a preexisting lithosphericscale weakness zone may be a major parameter in controlling the characteristics of natural oblique rifts not only in terms of fault pattern as outlined by previous experiments but also in terms evolution, architecture and strain partitioning. In particular, strong differences in these parameters have been observed between low- to moderate- and highobliquity rifting, with the main changes in the deformation styles occurring for obliquity $\sim 30^{\circ}$ \% $45^{\circ}$ (angle between the orthogonal to the rift trend and the direction of extension), which marks the transition from extension- to strike-slip-dominated deformation.

[55] Modeling results may have a general relevance for natural oblique rifts, and may help in the interpretation of complex geological data from these extensional settings.

\section{Acknowledgments}

[56] We warmly thank Marco Bonini, Giorgio Ranalli, Federico Sani, and Jolante Van Wijk for discussions. We also thank Francesco Mazzarini for suggestions and for providing the program used to calculate the weighted fault orientation. Detailed and constructive comments by the Associate Editor Luc Lavier, an anonymous reviewer, and the Editor Thorsten Becker helped to improve the manuscript. Research was supported by CNR funds (RSTL 105 "Evoluzione della parte Nord del rift Afroarabico e distribuzione regionale delle georisorse" and PNRA project 2004/4.1).

\section{References}

Afonso, J. C., and G. Ranalli (2004), Crustal and mantle strengths in continental lithosphere: Is the jelly sandwich model obsolete?, Tectonophysics, 394, 221-232, doi:10.1016/j.tecto.2004.08.006.

Bastow, I. D., G. W. Stuart, J. M. Kendall, and C. J. Ebinger (2005), Upper mantle seismic structure in a region of incipient continental breakup: Northern Ethiopian rift, Geophys. J. Int., 162(2), 479-493, doi:10.1111/j.1365-246X.2005. 02666.x.

Bastow, I. D., A. A. Nyblade, G. W. Stuart, T. O. Rooney, and M. H. Benoit (2008), Upper mantle seismic structure beneath the Ethiopian hot spot: Rifting at the edge of the African low-velocity anomaly, Geochem. Geophys. Geosyst., 9, Q12022, doi:10.1029/2008GC002107.

Bellahsen, N., M. Fournier, E. d'Acremont, S. Leroy, and J. M. Daniel (2006), Fault reactivation and rift localization: Northeastern Gulf of Aden margin, Tectonics, 25, TC1007, doi:10.1029/2004TC001626.

Boccaletti, M., M. Bonini, R. Mazzuoli, B. Abebe, L. Piccardi, and L. Tortorici (1998), Quaternary oblique extensional tectonics in the Ethiopian Rift (Horn of Africa), Tectonophysics, 287, 97-116, doi:10.1016/S0040-1951(98)80063-2.

Bonini, M., T. Souriot, M. Boccaletti, and J. P. Brun (1997), Successive orthogonal and oblique extension episodes in a rift zone: Laboratory experiments with application to the Ethiopian Rift, Tectonics, 16, 347-362, doi:10.1029/ 96TC03935.

Brun, J.-P. (1999), Narrow rifts versus wide rifts: Inferences for the mechanics of rifting from laboratory experiments, Philos. Trans. R. Soc. London, Ser. A, 357, 695-712, doi:10.1098/rsta.1999.0349.

Brun, J.-P., and V. Tron (1993), Development of the North Viking Graben: Inferences from laboratory modelling, Sediment. Geol., 86, 31-51, doi:10.1016/0037-0738(93)90132-O.

Clifton, A. E., and R. W. Schlische (2001), Nucleation, growth, and linkage of faults in oblique rift zones: Results 
from experimental clay models and implications for maximum fault size, Geology, 29, 455-458, doi:10.1130/00917613(2001)029<0455:NGALOF>2.0.CO;2.

Clifton, A. E., and R. W. Schlische (2003), Fracture populations on the Reykjanes Peninsula, Iceland: Comparison with experimental clay models of oblique rifting, J. Geophys. Res., 108(B2), 2074, doi:10.1029/2001JB000635.

Clifton, A. E., R. W. Schlische, M. O. Withjack, and R. V. Ackermann (2000), Influence of rift obliquity on fault-population systematics: Results of experimental clay models, J. Struct. Geol., 22, 1491-1509, doi:10.1016/S01918141(00)00043-2.

Corti, G. (2008), Control of rift obliquity on the evolution and segmentation of the main Ethiopian rift, Nat. Geosci., 1, 258-262, doi:10.1038/ngeo160.

Corti, G. (2009), Continental rift evolution: From rift initiation to incipient break-up in the Main Ethiopian Rift, East Africa, Earth Sci. Rev., 96, 1-53, doi:10.1016/j.earscirev.2009. 06.005 .

Corti, G., and P. Manetti (2006), Asymmetric rifts due to asymmetric Mohos: An experimental approach, Earth Planet. Sci. Lett., 245, 315-329, doi:10.1016/j.epsl.2006. 02.004.

Corti, G., M. Bonini, F. Innocenti, P. Manetti, and G. Mulugeta (2001), Centrifuge models simulating magma emplacement during oblique rifting, J. Geodyn., 31, 557-576, doi:10.1016/S0264-3707(01)00032-1.

Corti, G., M. Bonini, S. Conticelli, F. Innocenti, P. Manetti, and D. Sokoutis (2003), Analogue modelling of continental extension: A review focused on the relations between the patterns of deformation and the presence of magma, Earth Sci. Rev., 63, 169-247, doi:10.1016/S0012-8252(03) 00035-7.

Corti, G., M. Bonini, D. Sokoutis, F. Innocenti, P. Manetti, S. Cloetingh, and G. Mulugeta (2004), Continental rift architecture and patterns of magma migration: A dynamic analysis based on centrifuge models, Tectonics, 23, TC2012, doi:10.1029/2003TC001561.

Dauteuil, O., and J. P. Brun (1993), Oblique rifting in a low spreading ridge, Nature, 361, 145-148, doi:10.1038/ $361145 \mathrm{a} 0$.

Dauteuil, O., and J. P. Brun (1996), Deformation partitioning in a slow spreading ridge undergoing oblique extension: Mohns Ridge, Norwegian Sea, Tectonics, 15, 870-884, doi:10.1029/95TC03682.

Dauteuil, O., P. Huchon, F. Quemeneur, and T. Souriot (2001), Propagation of an oblique spreading centre: The western Gulf of Aden, Tectonophysics, 332, 423-442, doi:10.1016/ S0040-1951(00)00295-X.

Dunbar, J. A., and D. S. Sawyer (1989), Continental rifting at pre-existing lithospheric weaknesses, Nature, 242, 565-571.

Ebinger, C. (2005), Continental breakup: The East African perspective, Astron. Geophys., 46, 2.16-2.21.

Ebinger, C., and N. H. Sleep (1998), Cenozoic magmatism throughout east Africa resulting from impact of a single plume, Nature, 395, 788-791, doi:10.1038/27417.

Fournier, M., and C. Petit (2007), Oblique rifting at oceanic ridges: Relationship between spreading and stretching directions from earthquake focal mechanisms, J. Struct. Geol., 29, 201-208, doi:10.1016/j.jsg.2006.07.017.

Kendall, J. M., G. W. Stuart, C. J. Ebinger, I. D. Bastow, and D. Keir (2005), Magma assisted rifting in Ethiopia, Nature, 433, 146-148, doi:10.1038/nature03161.
Keranen, K., and S. L. Klemperer (2008), Discontinuous and diachronous evolution of the Main Ethiopian Rift: Implications for the development of continental rifts, Earth Planet. Sci. Lett., 265, 96-111, doi:10.1016/j.epsl.2007.09.038.

Keranen, K., S. L. Klemperer, J. Julia, J. L. Lawrence, and A. Nyblade (2009), Low lower-crustal velocity across Ethiopia: Is the Main Ethiopian Rift a narrow rift in a hot craton?, Geochem. Geophys. Geosyst., 10, Q0AB01, doi:10.1029/2008GC002293.

Mart, Y., and O. Dauteuil (2000), Analogue experiments of propagation of oblique rifts, Tectonophysics, 316, 121-132, doi:10.1016/S0040-1951(99)00231-0.

McClay, K. R., and M. J. White (1995), Analogue modelling of orthogonal and oblique rifting, Mar. Pet. Geol., 12, 137-151, doi:10.1016/0264-8172(95)92835-K.

McClay, K. R., T. Dooley, P. Whitehouse, and M. Mills (2002), 4-D evolution of rift systems: Insights from scaled physical models, Am. Assoc. Pet. Geol. Bull., 86, 935-959.

Morley, C. K. (1999a), Influence of preexisting fabrics on rift structure, in Geoscience of Rift Systems: Evolution of East Africa, edited by C. K. Morley, AAPG Stud. Geol., 44, $151-160$

Morley, C. K. (1999b), How successful are analogue models in addressing the influence of pre-existing fabrics on rift structures?, J. Struct. Geol., 21, 1267-1274, doi:10.1016/ S0191-8141(99)00075-9.

Mulugeta, G., and W. Ghebreab (2001), Modeling heterogeneous stretching during episodic or steady rifting of the continental lithosphere, Geology, 29, 895-898, doi:10.1130/ 0091-7613(2001)029<0895:MHSDEO>2.0.CO;2.

Ramberg, H. (1981), Gravity, Deformation and the Earth's Crust, 452 pp., Academic, London.

Ranalli, G. (1995), Rheology of the Earth, 2nd ed., 413 pp., Chapman and Hall, London.

Smith, J. V., and D. W. Durney (1992), Experimental formation of brittle structural assemblages in oblique divergence, Tectonophysics, 216, 235-253, doi:10.1016/0040-1951(92) 90399-Q.

Sokoutis, D., G. Corti, M. Bonini, J.-P. Brun, S. Cloetingh, T. Mauduit, and P. Manetti (2007), Modelling the extension of heterogeneous hot lithosphere, Tectonophysics, 444, 63-79, doi:10.1016/j.tecto.2007.08.012.

Tommasi, A., and A. Vauchez (2001), Continental rifting parallel to ancient collisional belts: An effect of the mechanical anisotropy of the lithospheric mantle, Earth Planet. Sci. Lett., 185, 199-210, doi:10.1016/S0012-821X(00)00350-2.

Tron, V., and J. P. Brun (1991), Experiments on oblique rifting in brittle-ductile systemsTectonophysics, 188, 71-84, doi:10.1016/0040-1951(91)90315-J.

van Wijk, J. W. (2005), Role of weak zone orientation in continental lithosphere extension, Geophys. Res. Lett., 32, L02303, doi:10.1029/2004GL022192.

van Wijk, J. W., and D. Blackman (2007), Development of en echelon magmatic segments along oblique spreading ridges, Geology, 35, 599-602, doi:10.1130/G23294A.1.

Versfelt, J., and B. R. Rosendahl (1989), Relationships between pre-rift structure and rift architecture in Lakes Tanganyika and Malawi: East Africa, Nature, 337, 354-357, doi:10.1038/337354a0.

Withjack, M. O., and W. R. Jamison (1986), Deformation produced by oblique rifting, Tectonophysics, 126, 99-124, doi:10.1016/0040-1951(86)90222-2.

Ziegler, P. A., and S. A. P. L. Cloetingh (2004), Dynamic processes controlling evolution of rifted basins, Earth Sci. Rev., 64, 1-50, doi:10.1016/S0012-8252(03)00041-2. 